\title{
Powder die filling under gravity and suction fill mechanisms
}

\author{
R. Baserinia ${ }^{1,2 *}$ I. C. Sinka ${ }^{2}$
}

1. School of Engineering and Sustainable Development, Faculty of Technology, De Montfort 5 University, Leicester, LE1 9BH, United Kingdom

2. Department of Engineering, University of Leicester, Leicester, LE1 7RH, United Kingdom

*Corresponding Author: Dr Reza Baserinia, School of Engineering and Sustainable Development, De Montfort University, The Gateway, Leicester, LE1 9BH, United Kingdom Tel: +44 (0) 1162013866

10 Email: reza.baserinia@dmu.ac.uk

Keywords: Die filling, Powder flow, Suction filling, Gravity filling, Rotary press

\begin{abstract}
In pharmaceutical tablet manufacturing, the powder formulation is filled into a die and compacted into a tablet using rigid punches. Die fill is important because it limits the productivity of tablet presses and determines key quality attributes of tablets including weight and content uniformity.
\end{abstract}

Die fill occurs due to gravity and suction fill mechanisms. A model linear shoe-die filling system has been instrumented with pressure measurement devices for detailed characterisation

20 of air pressure evolution as the powder mass is delivered in the die. Systematic experiments were carried out using a range of microcrystalline cellulose powders to explore the role of powder properties (such as particle size and bulk density) and operating parameters (such as shoe and die geometry, shoe and suction punch kinematics and powder filling level) on powder delivery. Existing models were found inadequate to describe the mass flow rate of powders under a diversity of gravity and suction filling conditions. The pressure measurements enabled the development of a new die fill model using the Buckingham $\Pi$ theorem. The model includes separate terms for the contribution of the mass of powder delivered under gravity and suction fill mechanisms. The experimental procedures required to extract model parameters are described. The model is applicable to the handling and dosing of fine and cohesive powders 
where small differences in air pressure have a significant impact on the powder flow process. The practical application of the model for predicting die filling behaviour in a high-speed rotary tablet press is demonstrated by assuming operating conditions of a typical rotary tablet press. This approach can be adapted to assist formulation design and process development for operations involving handling and dosing of fine and cohesive powder.

\section{1. Introduction}

Many of the powder products in industries such as pharmaceuticals, chemicals, metals and food are presented in the form of compacts. In pharmaceutical tablet manufacturing for instance, the powder formulation is fed into a die followed by compaction using rigid punches. In broad terms feeding systems can be classified into linear and rotary feeders. In linear feeding systems, a shoe filled with powder passes over the die opening and deposits the powder into the die cavity under gravity and/or suction fill mechanisms. Practically all commercial pharmaceutical tablets are manufactured on rotary tablet presses. Here, the powder formulation is fed into the die using rotating paddles inside a feed frame. The powder is compacted in two stages, precompression and main compression using the upper and lower punches and associated rollers.

The tablet is finally exited from the die using an ejection cam. The powder feeding mechanism of a typical rotary tablet press is illustrated in Figure 1 (Sinka, et al. 2004).

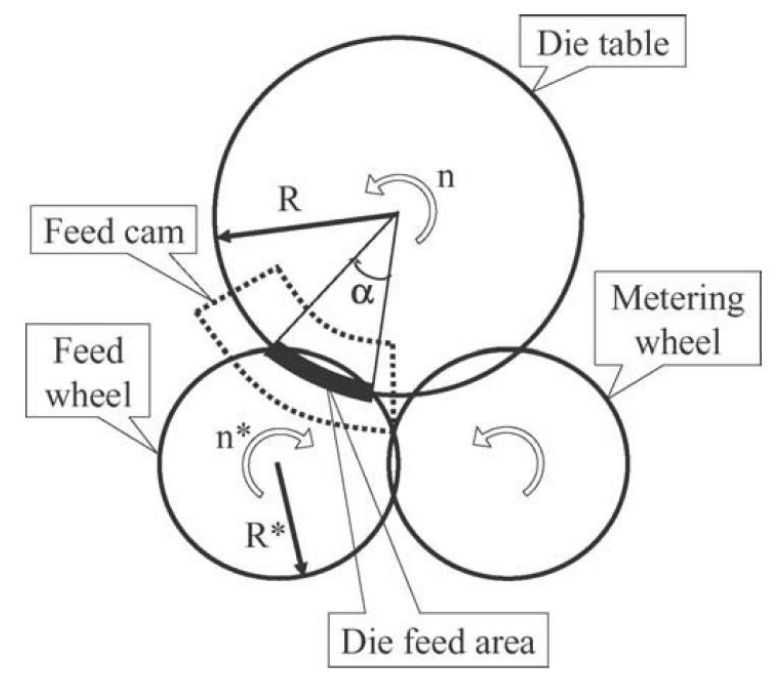

Figure 1 . Schematic diagram of a rotary feeding system in a rotary tablet press. Reprint from (Sinka, et al. 2004), with permission. 
Die fill is important because key properties of the tablets such as weight and content uniformity, are determined when the powder mass is delivered into the die prior to compaction. Therefore, it is important to describe the flow behaviour of powders under processing conditions representative to rotary tablet presses.

The flowability of powders can be characterised using a range of standard powder flow measurement techniques such as static and dynamic angle of repose (Carrigy 1970), critical orifice diameter (Jallo, et al. 2012; Vemavarapu, et al. 2009; Walker 1966), shear cell testing (Jenike 1964; Schulze 1994a; Schulze 1994b), bulk and tapped density measurements (Carr 1965; Grey and Beddow 1969), torque rheometers (Freeman 2004), etc. These methods can be used to compare the flowability of powder, but rank orders can be inconsistent when 60 comparing different techniques, e.g. when comparing static and dynamic methods (Baserinia, et al. 2016; Guyoncourt and Tweed 2003). Therefore, for effective formulation and process design, it is important to characterise powder flow using a technique which captures the interactions involved in the process under consideration (Sinka, et al. 2004). Specifically, for die fill, model linear shoe-die systems have been introduced by $\mathrm{Wu}$ and co-workers $(\mathrm{Wu}$,

65 Chuan-Yu, et al. 2003) to assess the influence of material properties and processing parameters in linear die fill systems. Bocchini (Bocchini 1987) observed that reducing the width of the die results in filling density reduction due to increased effect of loosely packed particles at the boundary layers close to the die walls. The influence of die geometry and orientation (relative top shoe direction) on density variations was highlighted by Haskins (Haskins and Jandeska 1999) using X-Ray CT images. They observed higher filling densities in areas along the axis of the shoe motion. $\mathrm{Wu}$ (Wu, C. Y., et al. 2004) used metallographic techniques to determine density variation in stepped dies and observed low density regions at the corner of the step in the die. Burch (Burch, et al. 2007) observed local powder densification at the top of the when multiple passes of the shoe was used. They attributed this to friction and shear effects acting over a short distance below shoe and die interface. Sawayama (Sawayama and Seki 1999) showed that height of the powder in the shoe, vibration and an air-replacement shoe can be used to increase die filling speed. Wu (Wu, Chuan-Yu, et al. 2003) introduced the concept of critical velocity defined as the maximum shoe velocity at which the die is filled completely. They proposed the critical velocity as a measure for powder flowability whereby a material 80 with larger critical velocity is ranked as better flowing. Schiano (Schiano, et al. 2017) examined the influence of particle size on the flowability of common pharmaceutical excipients in linear shoe-die systems and observed a strong correlation between the critical velocity and critical 
orifice diameter. Strictly, critical velocity is not a material property as it changes with different processing parameters including the size of the die and shoe. Therefore, the flowability ranking can differ for different feeding systems (Sinka and Cocks 2009). Air pressure effects have been observed and $\mathrm{Wu}$ (Wu, Chuan-Yu, et al. 2003) concluded that 1) the filling rate increased significantly for the experiments conducted in vacuum and 2) during die filling stage the air pressure in the die is increased as more powder enters the die which opposes further powder discharge into the cavity. Schneider (Schneider, et al. 2007) proposed a power law relation

90 between mass flow rate of the powder and shoe velocity and developed a model to predict powder mass introduced into a die as a function of shoe velocity. The results obtained from this model were in good agreement with the experiments conducted in vacuum. However, large discrepancies were observed for the results measured in air due to strong effect of air on the filling process. Furthermore, an effect called "suction fill”" was identified by Jackson (Jackson, 95 et al. 2007). They showed that the efficiency of die filling can be increase by up to 2.5 times using the suction fill effect in comparison with the experiments involving gravity only. Mills (Mills and Sinka 2013) investigated the influence of particle size and density under suction fill and showed that for relatively poor flowing powders (e.g. small particle size and lower bulk density) the suction mechanism is more effective than for good flowing powders. They 100 described the pressure changes inside the die in gravity and suction fill mechanisms using the two diagrams presented in Figure 2. In gravity fill, air pressure inside the die increases as powder is introduced. During nose flow (Wu, C. -Y and Cocks 2004), the air inside the die can escape easily while during bulk/intermittent flow (Schneider, et al. 2007; Wu, C. -Y and Cocks 2004) the air can only escape through the clearances in the system and through the powder bed inside the shoe resulting in increased air pressure in the die (Figure 2a) opposing further powder discharge. 
(a)

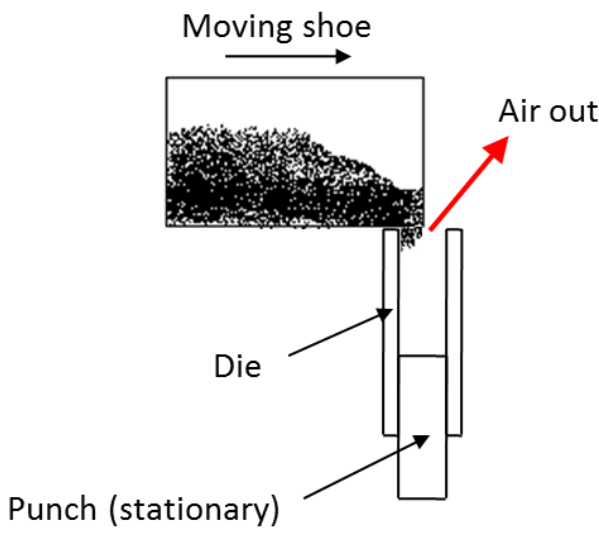

Stage 2: Bulk flow

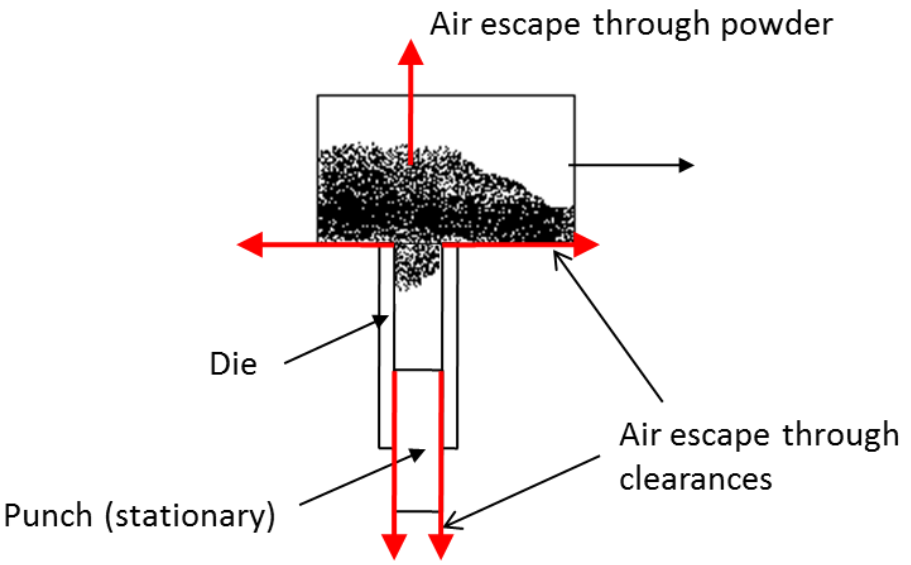

(b)

Stage 1

Stage 2

Stage 3

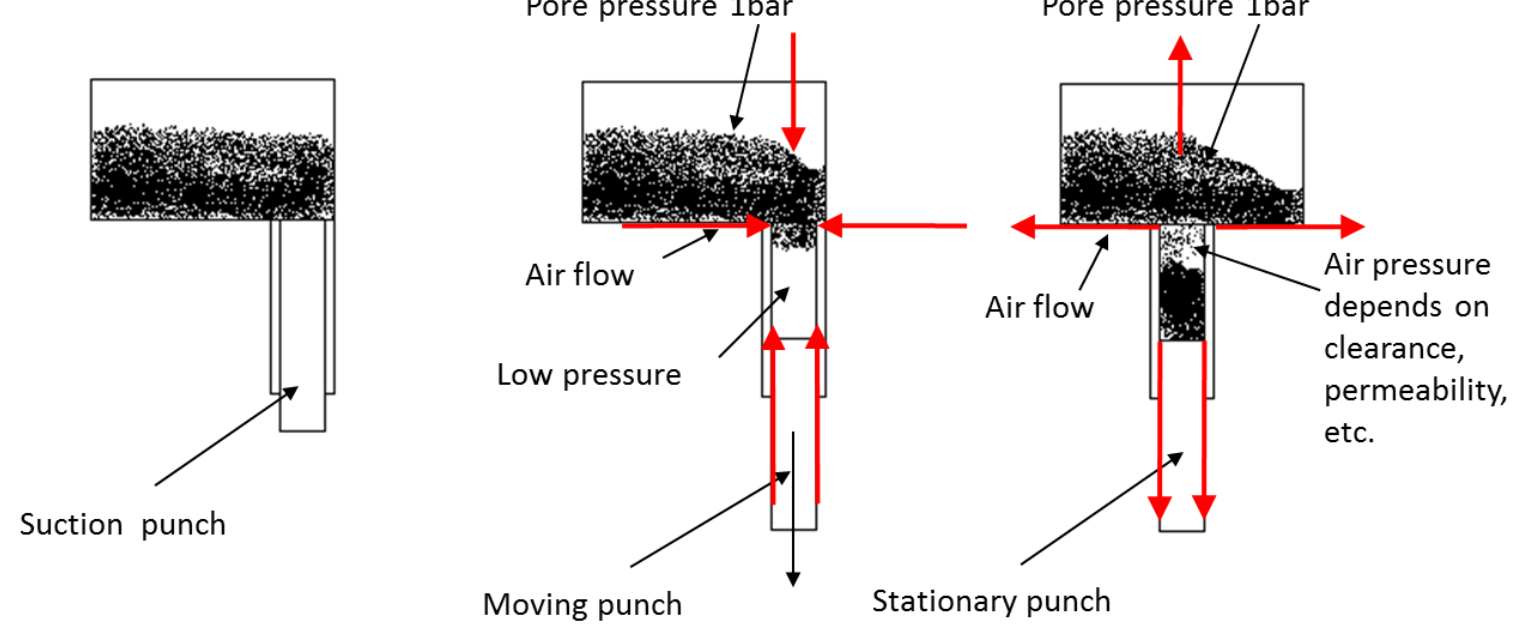

Figure 2. Schematic diagram of air flow mechanism during a) gravity fill and b) suction fill in linear shoe-die system. Reprint from (Mills and Sinka 2013), with permission.

110 In suction fill (Figure 2b), the die opening is initially covered by the suction punch. Downward motion of the punch creates a suction effect which facilitates powder flow into the die. At this stage, air can enter the die through the powder bed and the clearances in the system. Once the suction motion is finished, the powder is discharged into the die under gravity and as a result the air pressure inside the die starts to increase. The rising air pressure inhibits further powder

115 flow. At this stage, similar to gravity fill mechanism, the air inside the die can only escape through the powder bed and clearances.

Mendez (Mendez, et al. 2010) investigated the influence feed frame parameters in rotary feeding systems including blade speed and die disc speed on the flow behaviour of powders 
and stated that increasing the speed of blades and reducing the speed of the die table improves the flowability of the powder resulting in higher mass discharged into the die. On the contrary, Grymonpré (Grymonpré, et al. 2018) argued that high paddle speed can result in powder overlubrication and increase in tablet weight variation. They suggested altering the design of paddles as a method for improving die fill performance of rotary tablet presses. Zakhvatayeva (Zakhvatayeva, et al. 2018) examined the influence of material properties on the efficiency of

125 die filling in a rotary feeding system whereby the die cavity passes below a stationary shoe. They showed that critical filling velocity is increased for larger average particle size and permeability while for powders with higher cohesion and specific energy the die fill efficiency is reduced.

Computational studies of density variations in a stepped die were carried out by $\mathrm{Wu}(\mathrm{Wu}$,

130 Chuan-Yu and Cocks 2006) using DEM method. They observed low density regions close to the edge of the step where the powder flow in the narrow section merges with the flow in wide section. Guo (Guo, et al. 2009) used coupled CFD-DEM method to model a stationary die in both air and vacuum. They observed that in vacuum the mass flow rate of monodisperse and polydisperse powders is constant. They also showed that the impact of air on powder flow

135 reduces by increasing particle size and density and when the particle size and density are large enough, powder flow is no longer affected by air effect. Guo proposed a power law relationship to determine the mass flow rate in gravity fill based on the Archimedes number (Seville, et al. 2012) and the ratio of particle and air densities. This model was developed for a stationary shoe and cannot readily be used to predict mass flow rate in linear feeding systems. Also, 140 Archimedes number is highly sensitive to the particle size which necessitates precise characterisation of the size and selection of an appropriate representative value. $\mathrm{Wu}(\mathrm{Wu}$, Chuan-Yu and Guo 2012) further examined the effects of suction fill in linear feeding system using CFD-DEM and showed that powder mass flow rate in air under suction fill mechanism is equal to the mass flow rate under gravity in vacuum.

145 The models developed using empirical data (Schneider, et al. 2007) or numerical methods (Guo, et al. 2009) do not include the influence of parameters such as powder height in the shoe, air pressure in the die and suction velocity. Also, the empirical constants incorporated into these models change drastically by altering the processing parameters which hinder the application of these models for different practical situations. Therefore, there is a need for a more general model to predict powder flow behaviour in linear feeding systems. 
The purpose of this paper is to propose a powder flow model that incorporates air pressure effect to describe die fill behaviour of typical pharmaceutical powders. Empirical data is produced using a model shoe die system and the use of the model to predict powder performance on rotary presses is demonstrated. Systematic experiments have been carried out

155 to investigate the influence of processing parameters including powder height in the shoe, height of the die, shoe velocity and suction velocity as well as material dependent parameters on the flow behaviour of particulate materials in linear shoe-die feeding systems. The influence of force feeding which appears in production rotary tablet presses is not considered. The experimental system was designed to include instrumentation to measure the air pressure evolution inside the die during filling process to investigate particle-air interactions. The experimental results were analysed using the existing models which were not able to describe the empirical observations. New dimensional models were developed to capture air-powder interactions under gravity and suction fill mechanisms for linear die fill systems. A procedure is described to use the models to estimate powder performance under rotary tablet press 165 conditions to enable material and process optimisation for high-volume pharmaceutical manufacturing.

\section{Materials}

Four grades of microcrystalline cellulose (MCC), Avicel PH101, PH102, PH200 and PH302, manufactured by FMC BioPolymer, were selected. These materials are pharmaceutical

170 excipients used in direct compression and wet granulation formulation of tablets. The properties of the powders are summarised in Table 1. The average particle sizes presented are the nominal values provided by the manufacturer while the critical orifice diameter and the angle of repose were determined using procedures described elsewhere (Baserinia, et al. 2016). The bulk density was determined using the mass of full die and its volume. The particle size

175 distribution of materials presented in Figure 3 were measured using a Malvern Mastersizer 2000. Comparison of the results obtained for PH101, PH102 and PH200 with similar bulk density enables identifying the influence of particle size in the process. For PH102 and PH302 the average particle size is similar, and comparison of the results obtained for these powders can demonstrate the influence of bulk density. However, it must be noted that based on the particle size distributions (Figure 3), PH302 has larger proportion of fine particles compared to PH102 and the difference in flow behaviour could be the result of wider span in the particle size. Therefore, direct comparison of the results must be made with caution. Scanning Electron 
Microscopy (SEM) images of the materials were captured using an XL30 ESEM system manufactured by Philips which are presented in Figure 4.

Table 1. Summarised properties of the four grades of MCC used

\begin{tabular}{|c|c|c|c|c|}
\hline Material & $\begin{array}{c}\text { Average Particle } \\
\text { Size } \mu \mathrm{m}^{*}\end{array}$ & $\begin{array}{c}\text { Bulk Density, } \\
\mathrm{g} / \mathrm{ml}\end{array}$ & $\begin{array}{c}\text { Critical Orifice } \\
\text { Diameter, mm** }\end{array}$ & Angle of Repose, ${ }^{\circ * *}$ \\
\hline PH101 & 50 & 0.314 & 30 & 45 \\
\hline PH102 & 100 & 0.314 & 26 & 40 \\
\hline PH200 & 180 & 0.352 & 11 & 34 \\
\hline PH302 & 100 & 0.388 & 24 & 45 \\
\hline
\end{tabular}

* Provided by the manufacturer.

** Measured using the procedures described in reference (Baserinia, et al. 2016).

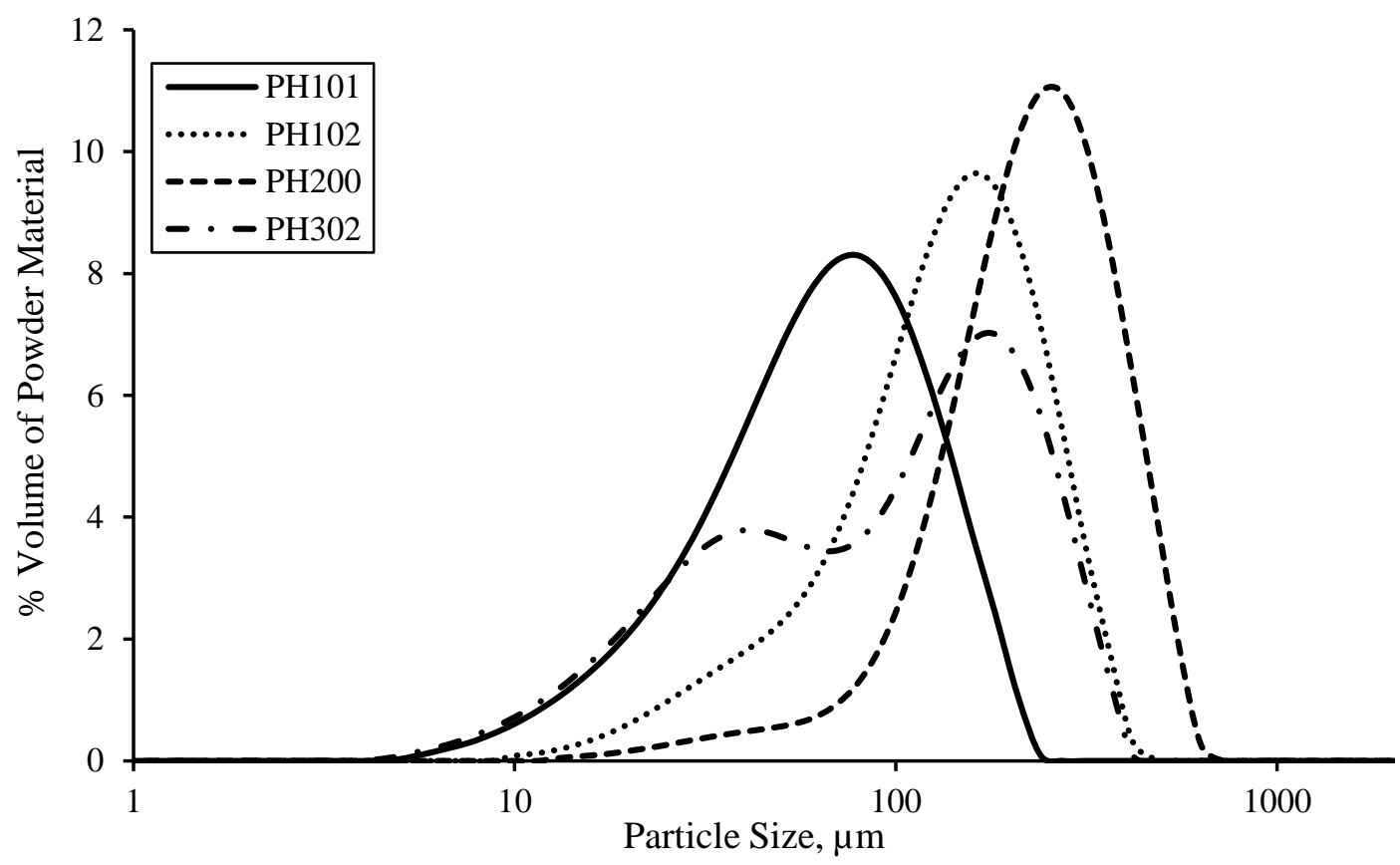

Figure 3. Particle size distribution of the four grades of MCC. 

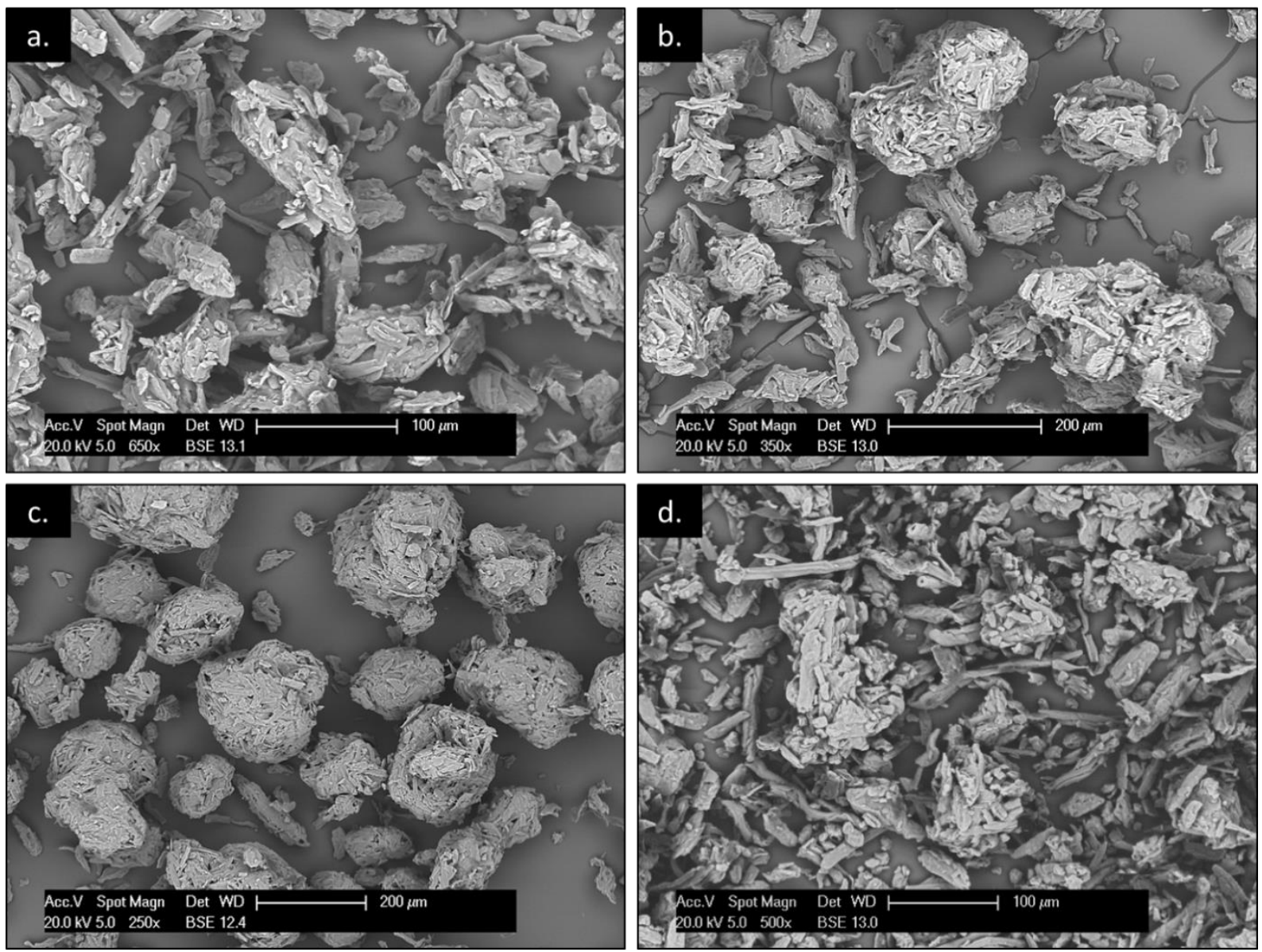

Figure 4. Secondary Electron Microscopy images of a) PH101, b) PH102, c) PH200 and d) PH302. Reprint from (Baserinia, et al. 2016), with permission.

In order to quantify the significance of particle-air interactions in the experiments conducted, powder permeability was determined at different consolidation stresses by means of a FT4 Powder Rheometer (Freeman 2007) using Nitrogen at $15{ }^{\circ} \mathrm{C}$ with its velocity set at $2 \mathrm{~mm} / \mathrm{s}$. The permeability values presented in Figure 5 were calculated using Darcy's law (Darcy 1856).

$$
Q=\frac{k A}{\mu} \frac{\Delta P}{L_{b}}
$$

where $Q, k, A, \mu, \Delta P$ and $L_{b}$ are volumetric flow rate of the fluid, powder permeability, crosssection area of powder bed, fluid viscosity, differential pressure across powder bed and length of powder bed, respectively. 


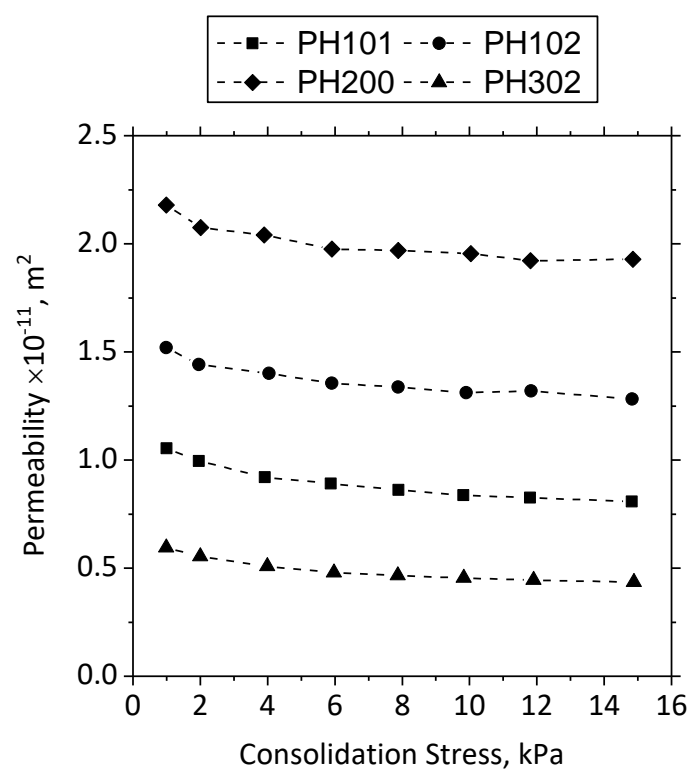

Figure 5. Permeability of four grades of Microcrystalline Cellulose.

\section{Development and calibration of the linear shoe-die feeding system}

The linear shoe-die system used in this study is illustrated in Figure 6. The system was introduced by $\mathrm{Wu}(\mathrm{Wu}, \mathrm{Chuan}-\mathrm{Yu}$, et al. 2003) and was further developed by Schneider (Schneider, et al. 2007). Jackson (Jackson, et al. 2007) modified the system to enable suction fill mechanism by gravity release of the punch inside the die. Mills (Mills and Sinka 2013) enhanced the system further by equipping the punch with a pneumatic actuator allowing precise control of the suction velocity. The linear shoe-die feeding system consists of a rectangular shoe of size $65 \times 31 \times 38 \mathrm{~mm}$ passing over a square die with opening size of $14 \times 14 \mathrm{~mm}$. It must be noted that this system does not incorporate the force feeding mechanism included in commercial rotary tablet presses.

For this study, the system was instrumented with two Sensirion SDP1000-L differential pressure transducers to measure the pressure difference between open atmosphere and 1) the

215 top of the die and 2) the bottom of the die through a channel in the punch as shown in Figure 6. Each pressure transducer has high and low inlet channels with the high channel connected to the die and low channel open to measure the atmospheric pressure at the vicinity of the die. The two pressure channel holes in the die wall and the punch have the diameter of $1 \mathrm{~mm}$ and were cleaned after each experiment to avoid blockage. 
220 The pressure transducers were calibrated using a hot-wire anemometer and a calibrated manometer where the steady flow of air results in a pressure drop inside the unit. Figure 7 shows a schematic diagram of the calibration system (Baserinia and Sinka 2018). The velocity of the shoe and the punch were calibrated using a high-speed video camera whereby the motion of the shoe and the punch was captured and the velocity was determined based on the fps of the video and the total number of frames captured for a set distance.

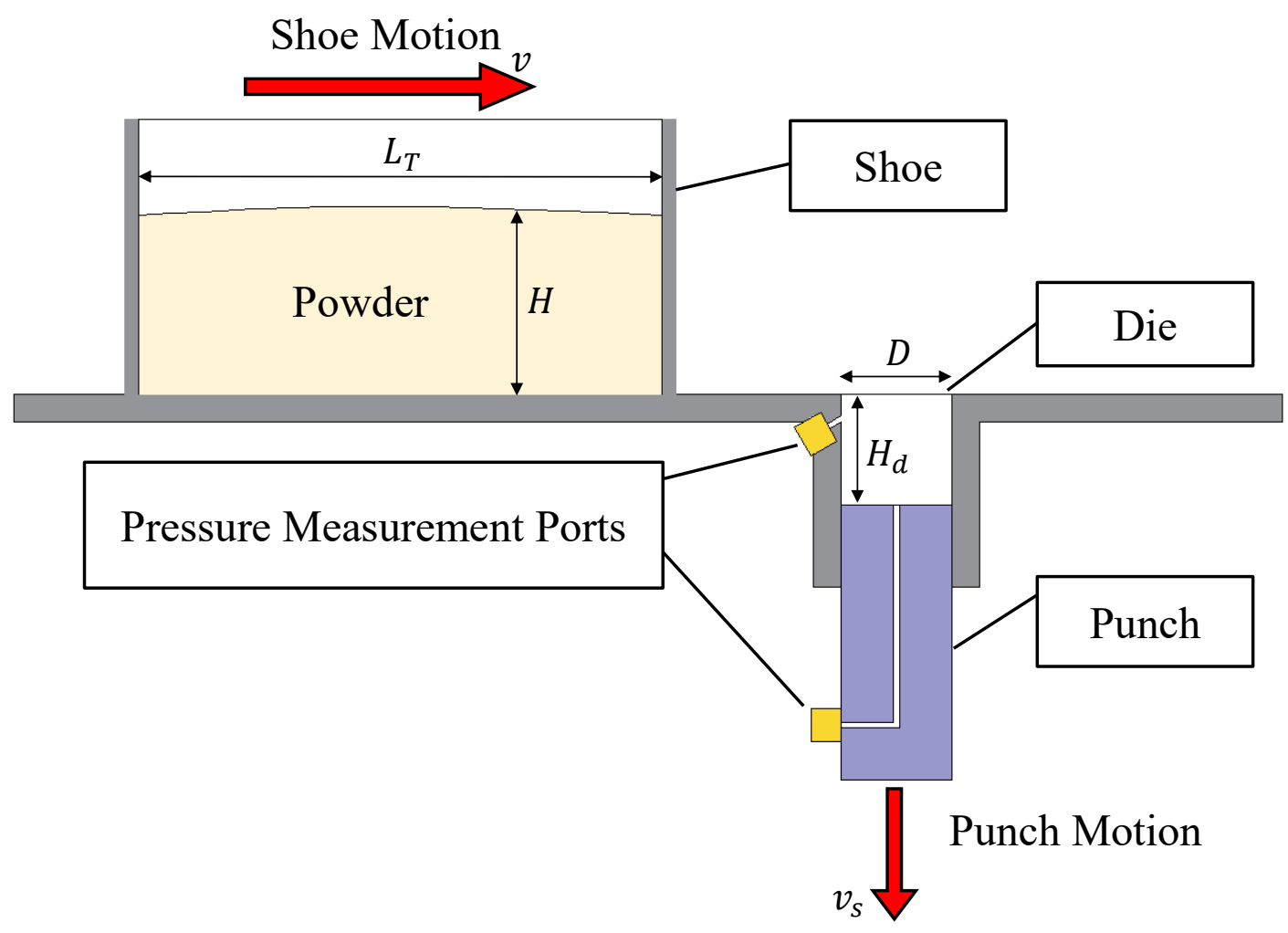

Figure 6. Schematic diagram of the linear shoe die filling system used in this paper.

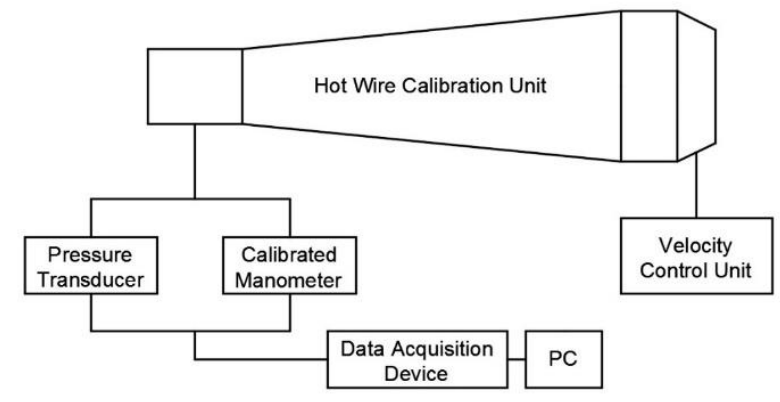

Figure 7. Schematic diagram of the pressure transducer calibration system. Reprint from

(Baserinia and Sinka 2018), with permission.

\section{Experimental procedure}


The test parameters used are summarised in Table 2. The powder was introduced into the shoe and the height of the powder $(H)$ was adjusted by levelling the top of the powder bed using a L-shaped rod.

235 Table 2. Summary of the processing parameters used in the experiments conducted under gravity and suction fill mechanisms

\begin{tabular}{|c|c|c|c|}
\hline $\begin{array}{c}\text { Powder Height }(\boldsymbol{H}), \\
\mathrm{mm}\end{array}$ & $\begin{array}{c}\text { Die Height }\left(\boldsymbol{H}_{\boldsymbol{d}}\right), \\
\mathrm{mm}\end{array}$ & $\begin{array}{c}\text { Shoe Velocity }(\boldsymbol{v}), \\
\mathrm{mm} / \mathrm{s}\end{array}$ & $\begin{array}{c}\text { Suction Velocity }\left(\boldsymbol{v}_{\boldsymbol{s}}\right), \\
\mathrm{mm} / \mathrm{s}\end{array}$ \\
\hline $15^{* \wedge}$ & $10^{*}$ & $30^{*}$ & $100^{\wedge}$ \\
$30^{*}$ & $20^{* \wedge}$ & $50^{*}$ & $150^{\wedge}$ \\
$40^{*}$ & & $100^{* \wedge}$ & $200^{\wedge}$ \\
& & $150^{*}$ & $250^{\wedge}$ \\
& & $200^{* \wedge}$ & $300^{\wedge}$ \\
& & $250^{*}$ & \\
\hline
\end{tabular}

* Used in the gravity fill experiments

$\wedge$ Used in the suction fill experiments

In gravity fill experiments, the height of the die $\left(H_{d}\right)$ was adjusted by lowering the punch inside

240 the die. The shoe then passed over the cavity with a set velocity $(v)$ depositing the powder inside the die.

For the experiments conducted in suction fill, the die was initially covered by the punch. The motion of the filled shoe with a set velocity was initiated and once the die opening was completely covered by the powder bed inside the shoe, the punch was lowered with a constant velocity $\left(v_{s}\right)$ creating the suction effect.

The velocity of the shoe and the punch in the die followed the diagram presented in Figure 8. At the start of the motion, the velocity increased linearly to the specified value with constant acceleration of $10 \mathrm{~m} / \mathrm{s}$. The shoe velocity was maintained constant during powder delivery into the die, followed by deceleration. 


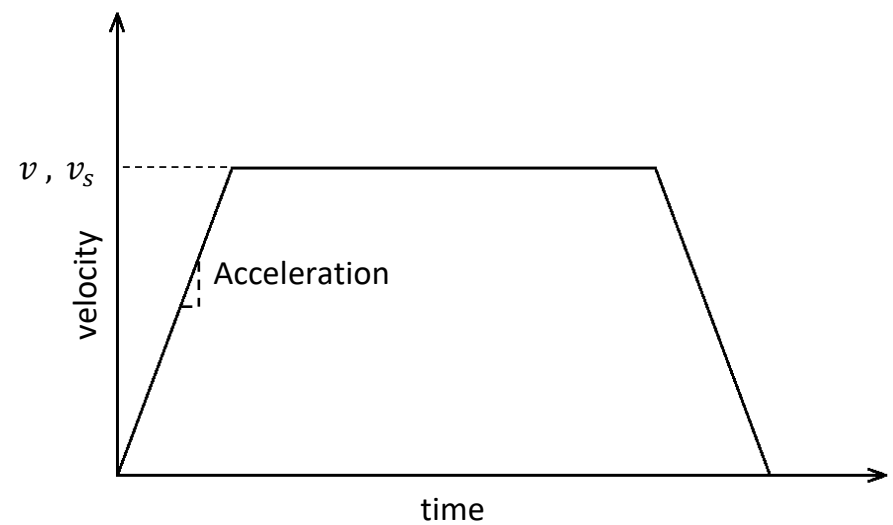

Figure 8. Velocity profile for the motion of the shoe and the punch

In both gravity and suction tests the powder inside the shoe was preconditioned before the experiment by shaking the shoe forward and backward for $\pm 5 \mathrm{~mm}$ with the velocity of 100 $\mathrm{mm} / \mathrm{s}$ to ensure consistent and repeatable initial conditions of the materials.

255 Each experiment was repeated three times. The mass of powder deposited in the die was weighted after each experiment. The pressure measurement data was logged using a data acquisition device (National Instruments) controlled with LabVIEW software. During initial experiments conducted for gravity fill (not reported here), it was observed that the pressures measured by the two transducers were very close to each other and the difference was smaller than the accuracy of the transducers. Also, for suction fill mechanism, since the hole inside the punch is rapidly covered with powder entering the die, the transducer connected at the bottom could not record the pressure changes during the experiment. For above reasons, all pressure data reported in this paper are measured by the top transducer only.

\section{Results and Discussions}

265 The gravity and suction fill mechanisms are described and discussed in this section. The pressure evolution profiles during these processes is key for powder delivery and the magnitudes are necessary for model development; for this reason the changes in the differential pressure between the die and open atmosphere are discussed in detail. New models are introduced to predict mass of powder discharged into the die as a function of shoe/suction velocity and the differential pressure between the die and open atmosphere.

\subsection{Gravity fill mechanism}




\subsubsection{Powder mass delivered and critical velocity}

The powder mass delivered into the die for different shoe velocities $(v)$ are presented in Figure 9 including the standard deviation from three repeat experiments. The labels represent the height of the powder in the shoe and height of the die, respectively. Consistent with previous studies (Jackson, et al. 2007; Mills and Sinka 2013; Schneider, et al. 2007; Wu, Chuan-Yu, et al. 2003), it was observed that:

- The powder mass introduced into the die reduces when the shoe velocity is increased.

- The powder mass is reduced when the height of the powder in the shoe is increased.

- Powder conditioning (through the initial back and forth motion of the shoe) and the initial acceleration of the shoe result in formation of a heap of powder.

- If the powder height in the shoe is relatively low, then the so called "nose flow" is observed (nose flow is described (Wu, Chuan-Yu, et al. 2003)).

- If the powder height in the shoe is relatively high, then "bulk flow" or "intermittent flow" mechanisms are observed. (bulk and intermittent flow is described (Schneider, et al. 2007)). For large values of powder heights in the shoe, the self-weight of the powder results in local densification and particle interlocking which inhibit powder flow. The powder bed also becomes less permeable (due to densification) and therefore air flow out of the die is reduced.

- As more powder enters the die, air pressure built up opposes further material discharge and results on the reduction of the mass delivered.

The experiments presented in Figure 9 include large powder height levels in the shoe. The results show that above a certain shoe velocity (e.g. for the relatively poor flowing PH101 and PH302 at shoe velocities above $100 \mathrm{~mm} / \mathrm{s}$ ) the mass delivered into the die remains nearly constant. 

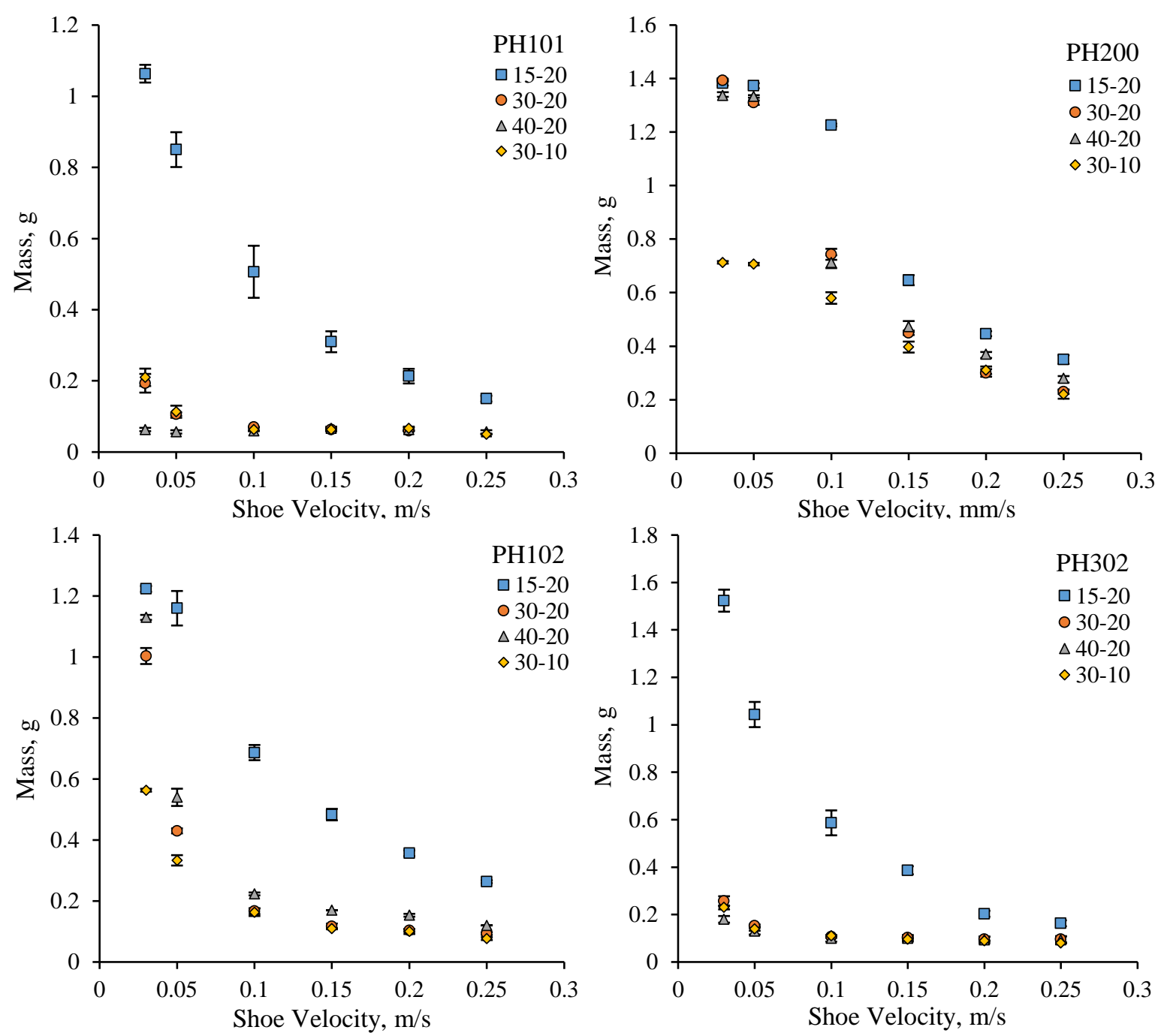

Figure 9. Mass of four grades of MCC introduced into the die under gravity fill mechanism vs. shoe velocity. The labels represent the powder height in the shoe and die height respectively.

300 The die filling results can be presented in terms of fill ratio $(\delta)$ defined as the ratio between the mass delivered and mass of the full die as illustrated in Figure 10. For experiments with similar $H$ but different $H_{d}$, it is observed that the mass of the powder delivered into the die is similar for a given material while the fill ratio changes since the volume of the die and so the mass of the full die is changed. Therefore, interpretation of the results presented in the form of fill ratio alone should be made with caution.

For the experimental results measured under gravity fill mechanism, the fill ratio relation defined by $\mathrm{Wu}\left(\mathrm{Wu}, \mathrm{Chuan}-\mathrm{Yu}\right.$, et al. 2003) was fitted to the data and the critical velocity, $v_{c}$, and the exponent $n$ were obtained which are presented in Table 3. In fitting this relation to the data, the experiments in which the die was filled completely were omitted. 


$$
\delta=\left(\frac{v_{c}}{v}\right)^{n}
$$

310 Comparing the data presented in Tables 1 and 3 shows that generally for powders that are ranked higher in terms of flowability based on the critical orifice diameter and angle of repose methods (Table 1), larger critical velocity is recorded. The critical velocity can be used as a measure of powder flowability as proposed by Wu [1]; however, similar to the previous studies (Mills and Sinka 2013; Sinka and Cocks 2009) discrepancies in the flow ranking of materials 315 are observed when the processing parameters are changed.

The parameter $n$ from the fill ratio relation appears in the dimensionless model developed by Schneider [7] (Equation 3). For this model, the empirical constant, $c$, was determined from fitting the experimental results. The values obtained are also presented in Table 3.

$$
\frac{m_{g}}{\rho_{b} D^{2} L}=c\left(\frac{v}{\sqrt{g D}}\right)^{-n}
$$

In Equation 3, $m_{g}, \rho_{b}, D, L$ and $g$ are the mass delivered in gravity fill, bulk density, width of die opening, length of the shoe and gravitational acceleration, respectively. Similar masses were delivered into the die for experiments conducted with $H=40 \mathrm{~mm}$ and $H_{d}=20 \mathrm{~mm}$ and the relation could not be fitted to the data points.

Comparing the values obtained for $c$ and $n$ show significant differences suggesting that they depend on the processing parameters selected (e.g. geometry, shoes speed, height of powder in the shoe). Thus, it is not possible to use this relationship without experimental calibration of the model for every set of processing parameters. Using dimensional analysis, a new model is proposed by modifying Schneider's model in Section 5.3.1. 

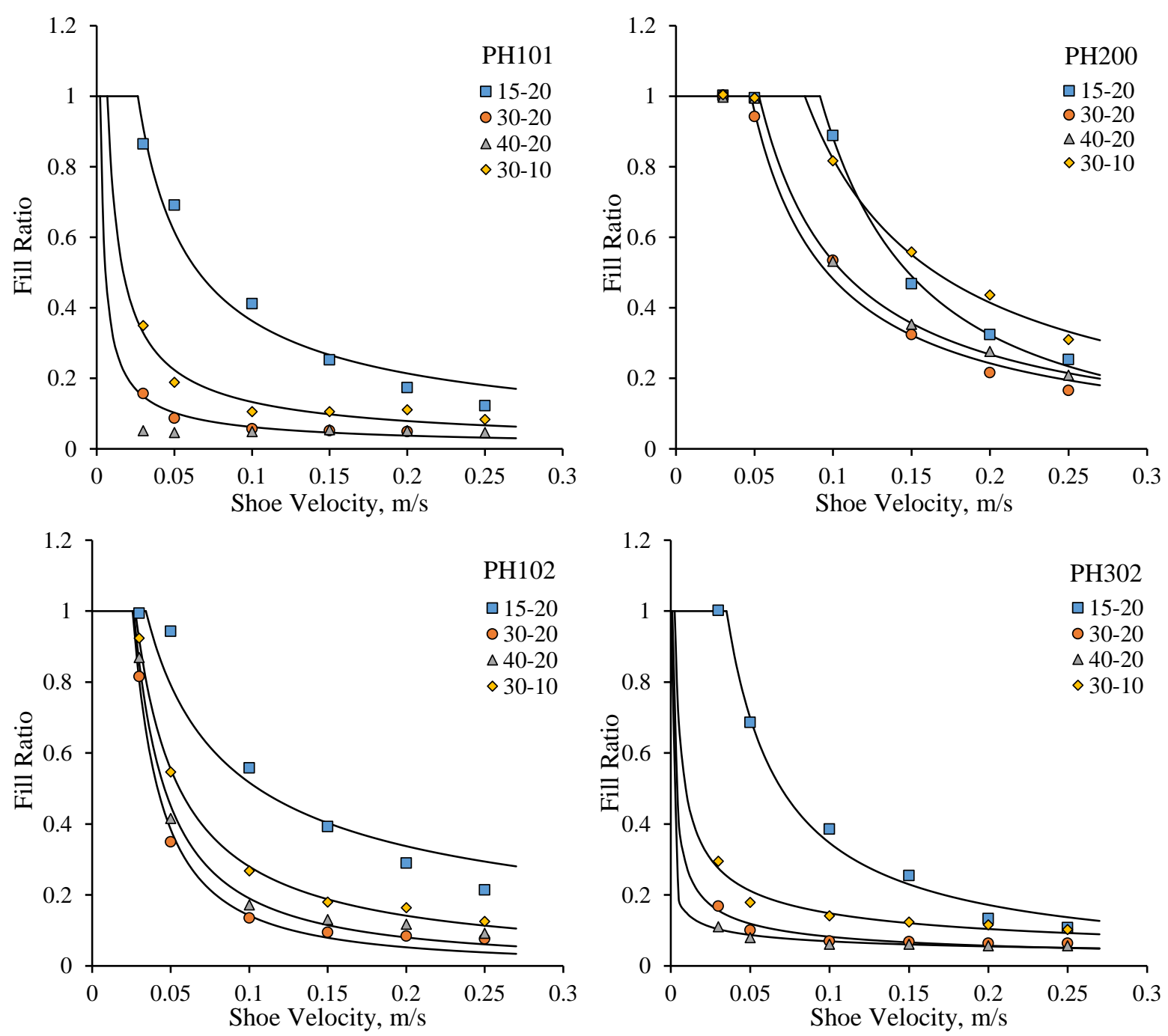

Figure 10. Fill ratio of four grades of MCC vs. shoe velocity for different height of the powder in the shoe and die heights. The fitted lines are determined using Equation 2.

Table 3. The parameters calculated from fitting the results to Equation 2 and 3.

\begin{tabular}{|c|c|c|c|c|c|c|c|c|c|c|c|c|}
\hline \multirow{2}{*}{ Material } & \multicolumn{3}{|c|}{$15-20$} & \multicolumn{3}{|c|}{$30-20$} & \multicolumn{3}{|c|}{$40-20$} & \multicolumn{3}{|c|}{$30-10$} \\
\cline { 2 - 14 } & $\begin{array}{c}v_{c} \\
\mathrm{~mm} / \mathrm{s}\end{array}$ & $n$ & $c$ & $\begin{array}{c}v_{c} \\
\mathrm{~mm} / \mathrm{s}\end{array}$ & $n$ & $c$ & $\begin{array}{c}v_{c} \\
\mathrm{~mm} / \mathrm{s}\end{array}$ & $n$ & $c$ & $\begin{array}{c}v_{c} \\
\mathrm{~mm} / \mathrm{s}\end{array}$ & $n$ & $c$ \\
\hline PH101 & 26 & 0.763 & 0.041 & 2 & 0.727 & 0.007 & - & - & - & 7 & 0.752 & 0.008 \\
\hline PH102 & 34 & 0.615 & 0.071 & 26 & 1.437 & 0.007 & 26 & 1.246 & 0.011 & 28 & 0.985 & 0.012 \\
\hline PH200 & 92 & 1.449 & 0.041 & 48 & 0.990 & 0.041 & 53 & 0.991 & 0.045 & 82 & 0.989 & 0.035 \\
\hline PH302 & 35 & 1.012 & 0.028 & 1 & 0.532 & 0.013 & 0 & 0.334 & 0.014 & 2 & 0.513 & 0.012 \\
\hline
\end{tabular}

\subsubsection{Differential pressure}

The magnitude and evolution of pressure in the die during suction and gravity fill mechanisms are discussed below. Selected pressure profiles are presented in Figure 11 for reference. In general, it is observed that the pressure in the die increases sharply when the mass delivery is 
initiated. The air pressure is then dissipated through the powder bed and the clearances in the system before going back to zero upon complete translation of the shoe over the die. At some stage during the delivery process, there will be a balance between pressure dissipation and pressure build-up (due to further introduction of powder mass) such that the pressure inside the 340 die remained approximately constant. This is more evident for PH101 at $v=50 \mathrm{~mm} / \mathrm{s}$. At higher shoe velocities, the delivery period is shorter and this effect is not significant.

For PH102, when the shoe velocity was set to $v=30 \mathrm{~mm} / \mathrm{s}$, a different pressure profile was observed compared to the rest of the experiments carried out (Figure 11c). It is believed that at this shoe velocity, the powder is discharged into the die gradually until the pressure is reached

345 the maximum value. Beyond this point, powder flow is reduced and the pressure is dissipated. For higher shoe velocities, the differential pressure profiles observed for PH102 were similar to the other grades of MCC. 


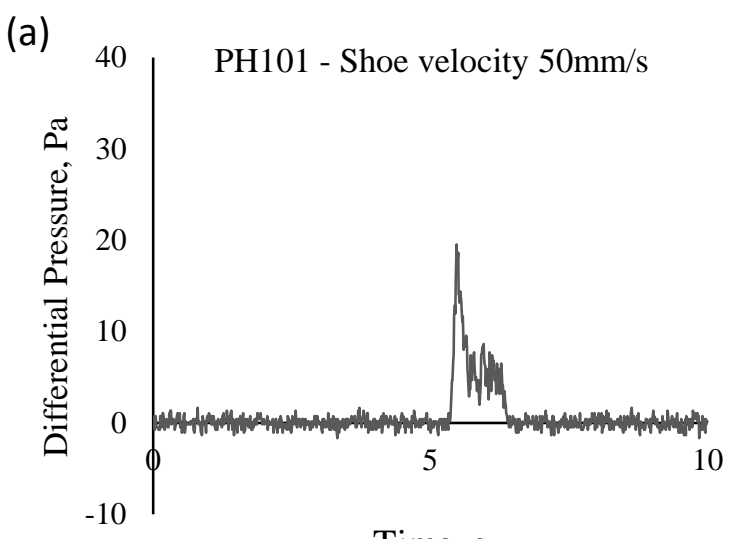

(b)

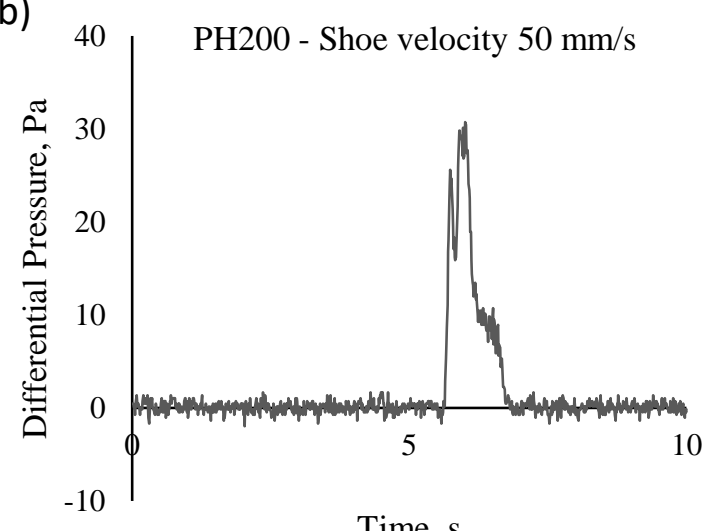

(c)

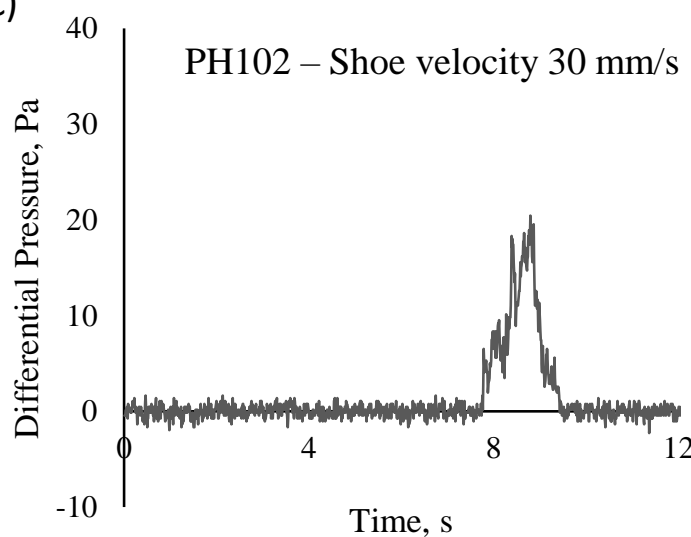

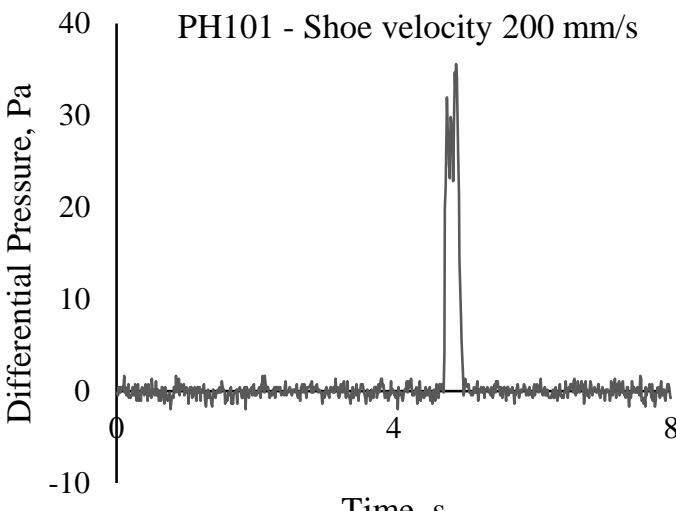

Time, $\mathrm{s}$

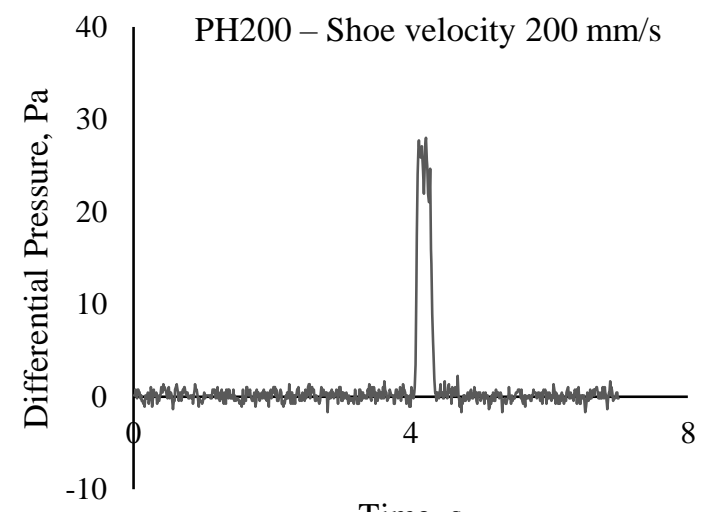

Time, $\mathrm{s}$

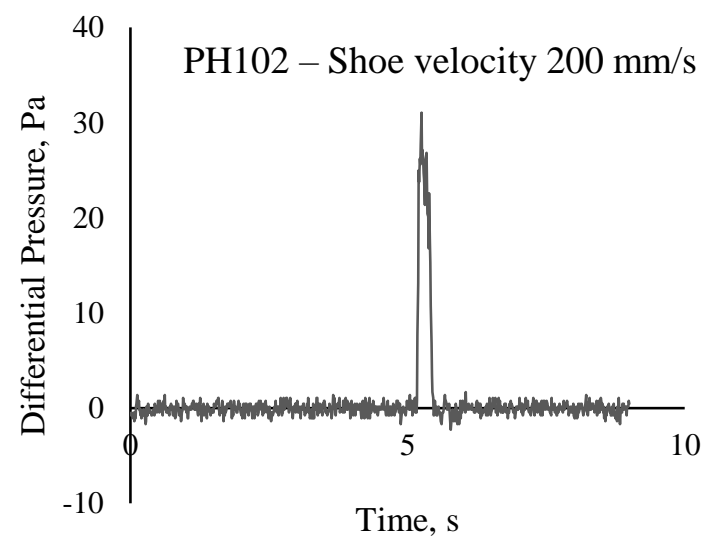

Figure 11. Differential pressure profile measured in gravity fill period for a) PH101, b) PH200 and c) PH102 under shoe velocities of 50 and $200 \mathrm{~mm} / \mathrm{s}$

The average differential pressure between the die and the ambient atmosphere measured for four grades of MCC are presented in Figure 12. The average values were calculated using the maximum pressures reached in the three repeat experiments. 

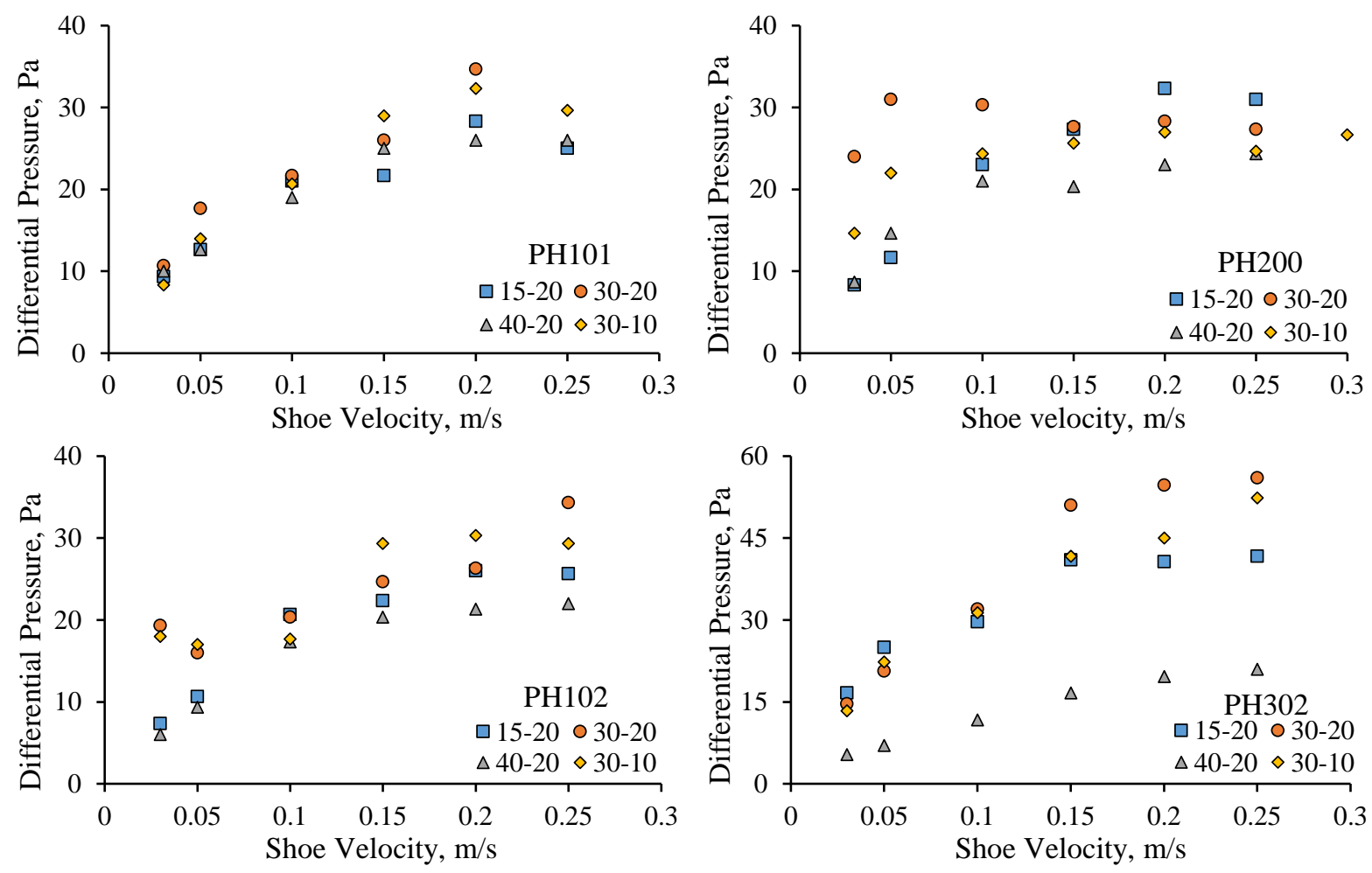

355 Figure 12. Average differential pressure between the die and ambient atmosphere measured for four grades of MCC during gravity fill vs. shoe velocity.

The air pressure effects are not similar for all the materials used. For PH101 and PH302 the differential pressure is increased significantly with shoe velocity while for PH200 the increase in pressure is small especially at high shoe velocities.

360 The differential pressure is a function of several parameters some of which are coupled. When the particles enter the die, the volume of the die that the air can occupy decreases resulting in an increase in the pressure. The air pressure build-up opposes further powder discharge. Also, while at high shoe velocities the mass delivered into the die remains nearly constant, the differential pressure increases with shoe velocity due to reduced dissipation. The pressurised air can escape through 1) the powder bed inside the shoe, and 2) the clearances in the system. For materials with smaller permeability (Figure 5) it is more difficult for air to escape through the bed and the pressure is mainly dissipated through the clearances. When the particles discharge into the die, powder dilation results in a negative pressure gradient opposite to powder flow direction inhibiting further powder discharge. On the other hand, larger voidage between the particles increases air permeability making it easier for air trapped inside the die to escape. For powders with higher permeability such as PH200 these parameters cancel each other to some extent resulting in small variations in the pressures developed in the die while 
for other materials the pressure is increased significantly by increasing the powder height and shoe velocity.

375 Comparison of the results obtained for PH102 and PH302 shows that for PH302 with higher bulk density (smaller permeability) the differential pressures recorded are larger and the pressures recorded for powders with smaller particle size are larger.

When the powder height in the shoe is larger, the lower levels of the bed are packed denser due to 1) self-weight of the material and 2) particle rearrangement resulted from initial shaking of the shoe. These result in reduction of permeability and air flow through the powder bed.

\subsection{Suction fill mechanism}

\subsubsection{Powder mass delivered under suction fill mechanism}

In suction fill experiments, the minimum suction velocity was selected based on the values of shoe velocities to ensure suction time is less than the time under which the die was fully covered by the shoe (length at which the die is fully covered is equal to the length of the shoe minus the width of the die). The mass of four grades of MCC discharged into the die using the testing conditions listed in Table 2 are presented in Figure 13. The error bars are generated using the standard deviation of the three repeat experiments. 

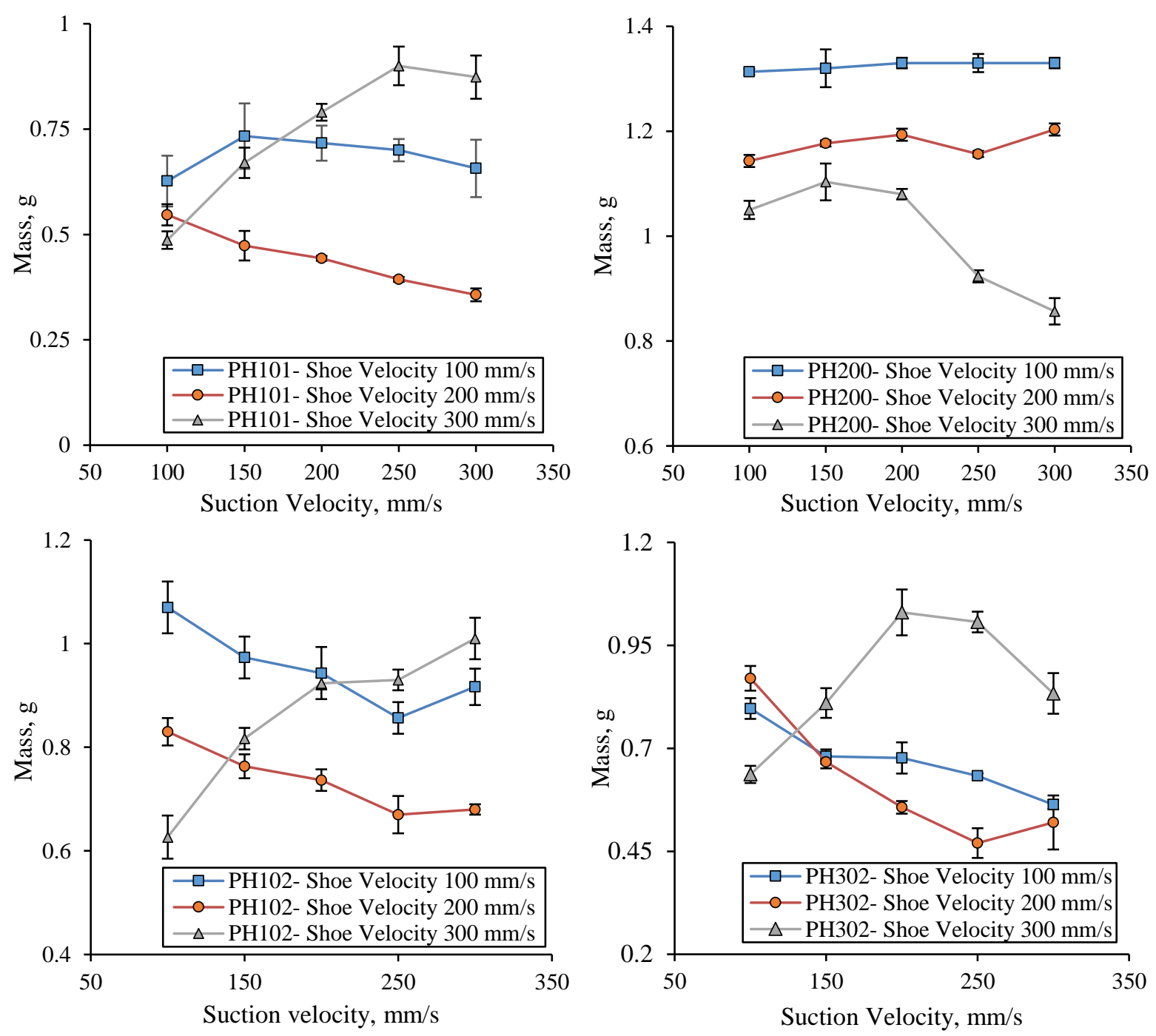

390 Figure 13. Mass of the powder delivered into the die in suction fill using different shoe velocities vs. suction velocity for four grades of MCC.

Comparison of the suction fill experimental results with gravity fill (Figure 9) shows that the efficiency of die filling increases significantly by employing suction. It is observed that the powder mass delivered into the die under gravity fill mechanism decreases by increasing the

395 shoe velocity. However, in suction fill the influence of shoe velocity on mass delivered changes based on the suction velocity selected. The extent of these effects varies for different materials.

In suction fill, powder flow is dependent on both suction and shoe velocities. The shoe can be considered "supply" while the suction is the "demand" or the driving force. For a specific supply level, increasing demand results in larger mass of the powder delivered into the die.

400 This was observed for PH101, PH102 and PH302 with $v=300 \mathrm{~mm} / \mathrm{s}$ (Figure 13). It is anticipated that increasing suction velocity results in increased mass discharge into the die. However, this is only true when the "supply" or shoe velocity is sufficiently large. In other 
words, for a given shoe velocity, there exist an optimum suction velocity at which the mass of the powder introduced is the largest and the reduction in the mass delivered at suction velocities above the optimum value is due to the reduction in the mass of the powder available at the vicinity of the die opening to be sucked into the die under the suction effect. It must be noted that the height of powder in the shoe is also a determining parameter in this regard since larger powder height means larger mass available to be sucked into the die.

For PH101 under the shoe velocity $v=100 \mathrm{~mm} / \mathrm{s}$, the mass of the powder introduced into the 410 die increased with suction velocity to its peak value at $v_{S}=150 \mathrm{~mm} / \mathrm{s}$ before decreasing for larger suction velocities. When the shoe velocity was set to $v=200 \mathrm{~mm} / \mathrm{s}$ no increase in the mass delivered was observed for the range of suction velocities considered and the mass decreased continuously. For $v=300 \mathrm{~mm} / \mathrm{s}$, although the mass of the powder introduced into the die was smaller than the mass delivered for $v=100$ and $200 \mathrm{~mm} / \mathrm{s}$ at $v_{s}=100 \mathrm{~mm} / \mathrm{s}$, increasing

415 suction velocity resulted in a large increase in the mass delivered such that at $v_{s}=200 \mathrm{~mm} / \mathrm{s}$ the mass of the powder introduced exceeded the mass delivered under smaller shoe velocities. Similar observations were made for PH102 and PH302.

For PH200, at $v=100 \mathrm{~mm} / \mathrm{s}$ and $v_{S}=100 \mathrm{~mm} / \mathrm{s}$, the die was completely filled with powder and increasing the suction velocity further had no effect (Figure 13). For $v=200 \mathrm{~mm} / \mathrm{s}$ minor 420 changes in the mass was observed as a result of increasing the suction velocity and the largest mass was delivered into the die at $v_{s}=300 \mathrm{~mm} / \mathrm{s}$. At $v=300 \mathrm{~mm} / \mathrm{s}$, the mass was increased by increasing the suction velocity and reached its maximum at $v_{S}=150 \mathrm{~mm} / \mathrm{s}$ before reducing for higher values. For PH200, the increase in the mass delivered is not as significant as those observed for other grades of MCC. For powders with larger particle size and smaller bulk 425 density (larger porosity) the effect of suction on die filling process is limited due to increased powder permeability. This is discussed in more detail in the next section.

Mills and Sinka (Mills and Sinka 2013) characterised powder flowability based on the critical velocity measured for a fixed suction velocity and observed some changes in the flow ranking order of the materials considered. However, it is shown that the mass introduced into the die at 430 a high shoe velocity can exceed the mass delivered under lower shoe velocity for a certain suction velocity (Figure 13). Therefore, it is not effective to fit the powder law relation proposed by $\mathrm{Wu}$ et al. ( $\mathrm{Wu}, \mathrm{Chuan}-\mathrm{Yu}$, et al. 2003) to determine the critical velocity for the experiments carried out under suction fill mechanism. 


\subsubsection{Differential pressure in suction fill mechanism}

435 Figure 14 illustrates schematically the pressure evolution in a die during a suction fill experiment. The average differential pressures for the suction and gravity fill mechanisms are presented in Table A.1. For suction fill, the differential pressure $\left(\Delta P_{S}\right)$ was taken as the minimum pressure recorded. For gravity fill, the differential pressure $\left(\Delta P_{g}\right)$ was taken as the difference between the minimum and maximum values of the pressure profile. During gravity

440 fill period, the mass discharge initiates while the pressure inside the die is still negative, and the pressure rise in the die may or may not exceed ambient pressure. Therefore, the maximum pressure values recorded are often relatively small. This is examined in more detail later in this section. A procedure is described in Section 5.3.1 to determine the differential pressure during gravity fill as a function of $v$ and $H$ which allows the estimation of $\Delta P_{g}$ for model development 445 for the suction fill experiments.

Figure 14 depicts four important features on the differential pressure profile: 1) the total delivery time which depends on the shoe velocity and the length of the shoe, 2) the suction fill delivery time which is determined by the velocity of the punch in the die and height of the die, 3) the gravity fill delivery time which depends on the total delivery time and the suction fill delivery period, and 4) the magnitude of the differential pressures in suction and gravity fill mechanisms. 


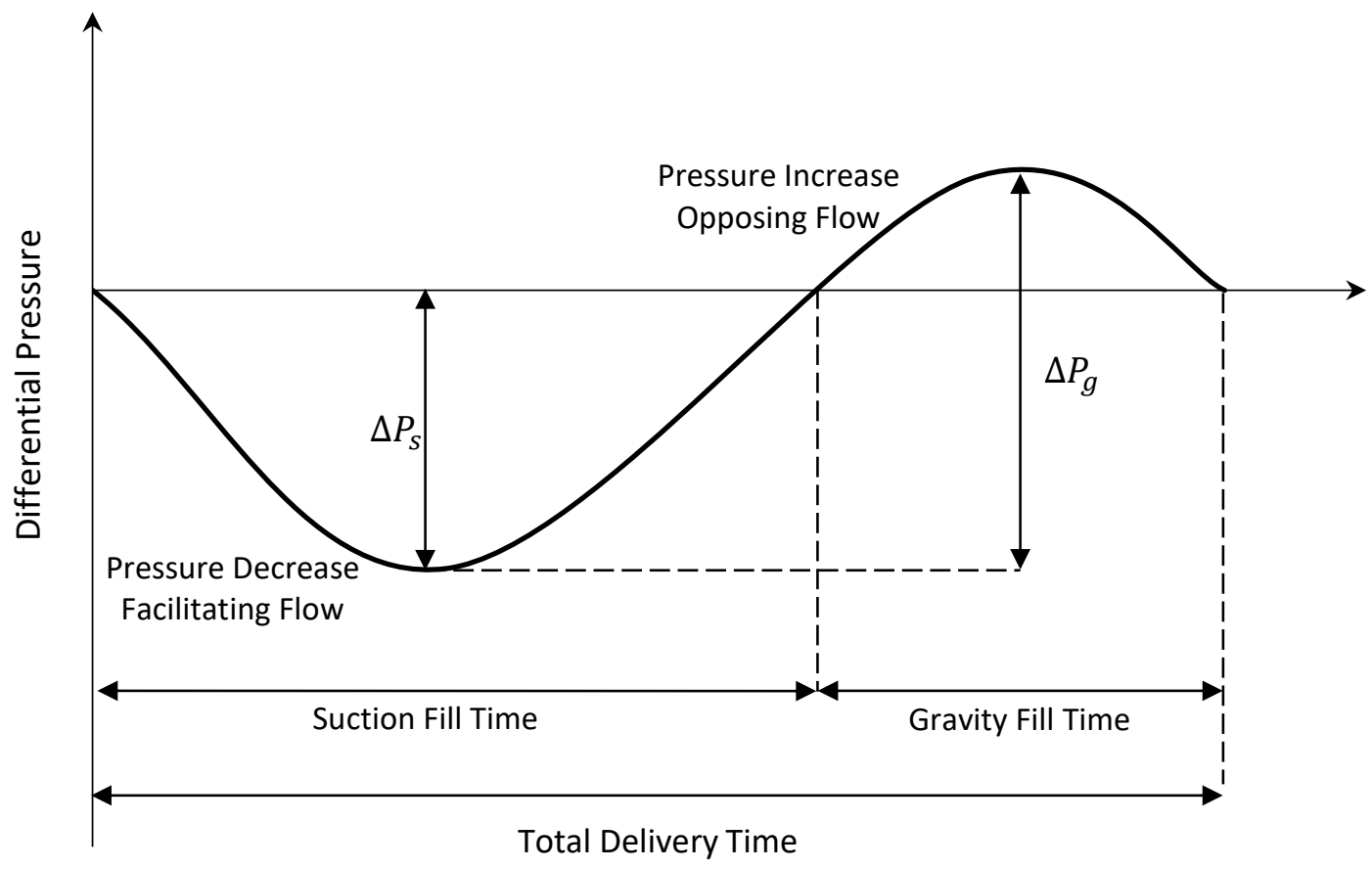

Figure 14. Schematic diagram of differential pressure changes between the die and ambient atmosphere during suction fill and gravity fill mechanisms.

455 Initially, the downward motion of the punch creates a suction effect which reduces the pressure inside the die and results in a pressure gradient in the direction of powder flow. This pressure gradient facilitates powder discharge into the die. After the initial acceleration the motion of the punch continues with constant velocity before decelerating to zero. In this period, velocity of the particles entering the die is increasing due to the initial acceleration while the punch

460 moves with a constant or reducing velocity. Therefore, the air which has entered the die through the powder bed and clearances in the system is compressed between the particles and the punch; and the pressure starts to increase towards the end of the suction period. Increasing pressure in the die opposes further flow of particles. The pressure increase continues after the suction fill period and the die fill mechanism switches to gravity fill.

465 This is demonstrated for PH101 using the pressure profiles presented in Figure 15. Similar pressure profiles are observed for other materials. Using the velocity of the shoe and the height of the die, the suction fill time can be calculated as $0.2,0.1$ and 0.067 seconds for suction velocities of 100, 200 and $300 \mathrm{~mm} / \mathrm{s}$ respectively (the actual times are somewhat longer due to acceleration and deceleration of the punch). In Figure 15, it is observed that the differential 470 pressure reaches minimum almost instantly after the suction fill initiates and it starts to rise before the suction is completed. 
The magnitude of the minimum and maximum pressures changes based on the shoe and suction velocities. For higher shoe velocities, the amount of powder delivered into the die after to the initial mass introduced under suction effect is limited and the rise in the pressure is less than 475 for smaller shoe velocities. As discussed before, since mass delivery under gravity initiates while pressure is negative, the pressure increase might not be sufficient (due to limited powder discharge during gravity fill) to generate a positive peak in the pressure profile.

For powders with higher permeability and large particle size, it is easier for air to enter the die during suction fill resulting in a smaller negative pressure gradient in the die and reduced 480 suction effect. Also, during gravity fill, since the air inside the die can escape more freely through the powder bed, the pressure gradient inhibiting powder flow is smaller thus the mass of the powder delivered in the die is higher. The results obtained for PH200 (Table A-1) show that the differential pressures measured during suction fill $\left(\Delta P_{S}\right)$ are similar across different shoe velocities while for the other grades of MCC the differential pressures are significantly 485 larger for $v=300 \mathrm{~mm} / \mathrm{s}$. 

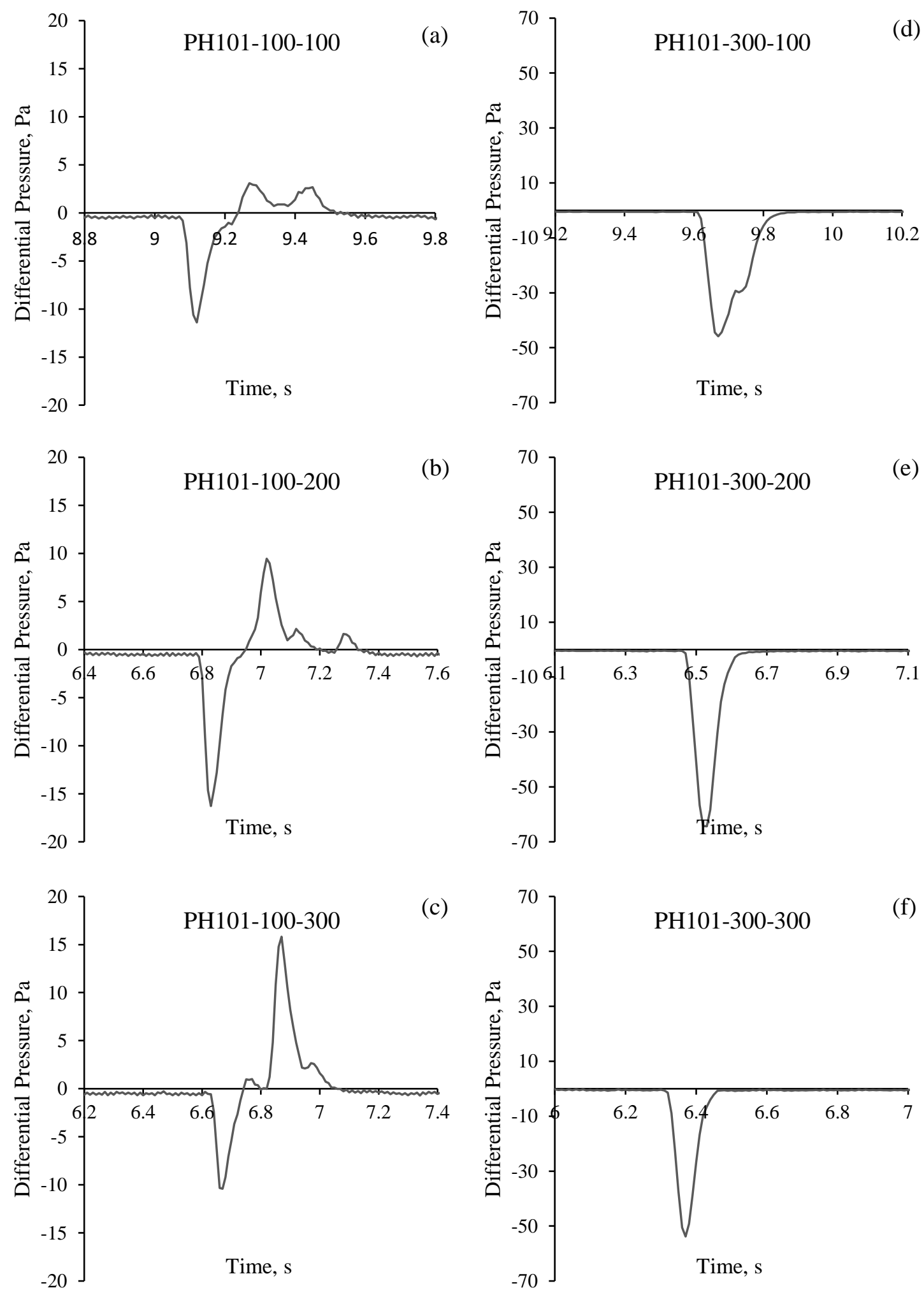

Figure 15. Differential pressure measured for PH101 using a) $v=100 \mathrm{~mm} / \mathrm{s}$ and $v_{s}=100 \mathrm{~mm} / \mathrm{s}$, b) $v=100 \mathrm{~mm} / \mathrm{s}$ and $\left.v_{s}=200 \mathrm{~mm} / \mathrm{s}, \mathrm{c}\right) v=100 \mathrm{~mm} / \mathrm{s}$ and $\left.v_{s}=300 \mathrm{~mm} / \mathrm{s}, \mathrm{d}\right) v=300 \mathrm{~mm} / \mathrm{s}$ and $v_{s}=100 \mathrm{~mm} / \mathrm{s}$, e) $v=300 \mathrm{~mm} / \mathrm{s}$ and $v_{s}=200 \mathrm{~mm} / \mathrm{s}$ and f) $v=300 \mathrm{~mm} / \mathrm{s}$ and $v_{s}=300 \mathrm{~mm} / \mathrm{s}$. 


\subsection{Model development}

In Section 5.1.1 it was shown that models existing in the literature cannot be used for linear shoe-die systems where air-powder interactions are important. The model developed by Schneider (Schneider, et al. 2007) cannot be used effectively since the coefficients included in the model change by altering the processing parameters. The model proposed by Guo (Guo, et al. 2009) was developed for stationary shoes and the influence of shoe motion is not incorporated into the model. Both these models are developed for gravity fill and not for suction fill mechanism. Therefore, the development of a new model is required. In the following sections, dimensional analysis is employed to develop new models through considering the influence of powder height in the shoe, suction velocity and the differential pressure developed between the die and open atmosphere during filling period.

\subsubsection{Gravity fill mechanism}

The model developed by Schneider to determine the mass of the powder introduced into the die as a function of shoe velocity was originally validated for the results measured in vacuum [4] and gave good predictions of the mass delivered. However, large scatter in the data was

505 observed for the experiments carried out in air. This model does not incorporate the effects of 1) air pressure built up inside the die on the mass delivered and 2) the influence of powder height in the shoe on densification of the particles and on powder permeability.

In developing Schneider's model the mass flow rate was assumed to be constant during the delivery period and a power law relation was proposed between the dimensionless mass flow rate in gravity fill mechanism $\left(\overline{\dot{m}_{g}}\right)$ and dimensionless shoe velocity $(\bar{v})$. This relation was rearranged to calculate the mass delivered into the die, $m_{g}$ (Equation 3). Here, Equation 3 is modified to include the effects of the powder height $(H)$ and the maximum differential pressure between the die and ambient atmosphere in gravity fill mechanism $\left(\Delta P_{g}\right)$. A number of other parameters are involved in this process including: viscosity of air $(\mu)$, coefficient of friction

515 between particles $\left(\mu_{p}\right)$ and between particles and the wall $\left(\mu_{p w}\right)$, powder permeability $(k)$, shape of the particles, adhesion between the particles and clearances in the system. Using the same independent parameters taken in the dimensional analysis (Gibbings 2011) carried out by Schneider (Schneider, et al. 2007) (bulk density $\left(\rho_{b}\right)$, gravitational acceleration $(g)$ and die width $(D))$, the dimensionless groups of $\bar{H}$ and $\overline{\Delta P}_{g}$ are formed as 


$$
\bar{H}=\frac{H}{D}
$$

520 and

$$
\overline{\Delta P}_{g}=\frac{\Delta P_{g}}{\rho_{b} g D}
$$

Therefore, it can be written that

$$
\overline{m_{g}}=f\left(\bar{v}, \bar{H}, \overline{\Delta P_{g}}, \mu, \mu_{p}, \mu_{p w}, k, \text { shape, adhesion, clearances }\right)
$$

where $\bar{m}$ and $\overline{v_{s}}$ are

$$
\overline{m_{g}}=\frac{m_{g}}{\rho_{b} D^{2} L}
$$

and

$$
\bar{v}=\frac{v}{\sqrt{g D}}
$$

According to the experimental results, similar to shoe velocity, the mass delivered into the die is inversely proportional to the differential pressure. A relation is proposed in the form of Equation 9 to determine the mass delivered. $\bar{v}$ and $\overline{\Delta P}$ are multiplied to form a new dimensionless group. The experimental results were fitted, and the values of the coefficients determined for each material are shown in Table 4. The experiments in which the die was completely filled were not considered in model development and an extra point was added with estimated values of $\Delta P_{g}, v$ equal to the critical velocity and $m_{g}$ as the mass of full die.

$$
\frac{m_{g}}{\rho_{b} D^{2} L}=c_{g}\left(\frac{H}{D}\right)^{a_{g}}\left(\frac{v \Delta P_{g}}{\rho_{b} g^{1.5} D^{1.5}}\right)^{n_{g}}
$$

Table 4 . The values of the coefficients $c_{g}, a_{g}$ and $n_{g}$ calculated from fitting the experimental data to Equation 9.

\begin{tabular}{|c|c|c|c|c|}
\hline Material & $c_{g}$ & $a_{g}$ & $n_{g}$ & $R^{2}$ \\
\hline PH101 & 0.047 & -2.446 & -0.485 & 0.97 \\
\hline PH102 & 0.037 & -0.970 & -0.651 & 0.88 \\
\hline PH200 & 0.043 & -0.697 & -0.911 & 0.92 \\
\hline PH302 & 0.040 & -3.043 & -0.673 & 0.98 \\
\hline
\end{tabular}


The mass delivered into the die calculated from Equation 9 using the coefficients presented in Table 4 are compared with the experimental measurements in Figure 16. It is observed that the model can be used to determine the mass with reasonable accuracy.

The calculated values of mass discharged using the model are mostly within $15 \%$ of the experimental values determined. This variation is larger than the acceptable weight variation for pharmaceutical tablets $( \pm 5 \%$ for tablets with weight above $324 \mathrm{mg}$ (United States Pharmacopeia and National Formulary[USP38-NF33] 2015)). However, it should be noted that

540 the results presented are for single pass of shoe while in rotary tablet presses there are additional force feed mechanisms due to multiple rapid passes of the paddles and the weight uniformity is ensured by a weight adjustment system (overfill/part eject).

It is shown that for materials with smaller particle size and higher bulk density, the magnitude of $a_{g}$ and consequently the effect of powder height in the shoe on the mass delivered is larger.

545 Since powder permeability is a function of both particle size and bulk density (Carman 1937; Kozeny 1927) it is anticipated that the values of $a_{g}$ are dependent on powder permeability. This is a valid consideration since for larger powder height in the shoe the particles are packed denser (especially at lower levels of the bed) after conditioning and powder permeability is reduced. It is also observed that $n_{g}$ changes with the average particle size where for PH102 and

550 PH302 with similar average particle sizes, the values of $n_{g}$ obtained are very close.

The coefficients in table 4 allow the model to be used for different processing parameters after calibration of the coefficients for the material and system in use.

The differential pressure developed inside the die should also be measured for the powder at the shoe velocities considered. This would require a large number of experiments to be carried 555 out. The following procedure is proposed to determine the values of $\Delta P_{g}$ using reduced number of experiments. 


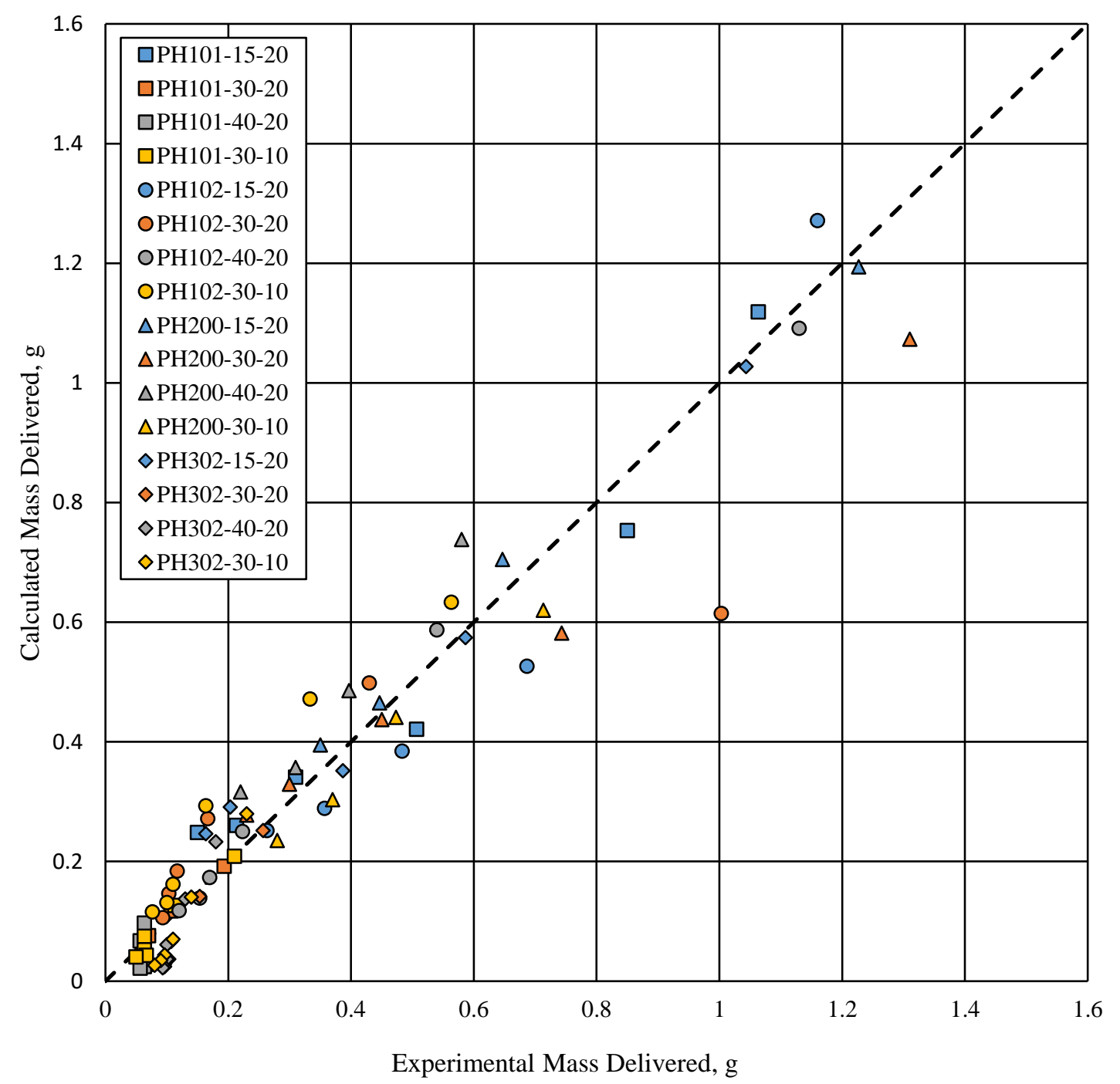

Figure 16. Experimental mass delivered into the die under gravity fill mechanism vs. the values calculated from Equation 9 using measured $\Delta P_{g}$.

560 As discussed previously, the differential pressure developed in the die during gravity fill changes with the height of powder inside the shoe $(H)$ and shoe velocity $(v)$. A polynomial fitting surface in the form of Equation 10 is proposed to determine the values of $\Delta P_{g}$.

$$
\Delta P_{g}=A_{00}+A_{10} v+A_{01} H+A_{20} v^{2}+A_{11} v H+A_{02} H^{2}
$$

This relation was fitted to the experimental results (excluding the experiments in which the die was filled completely) and the coefficients were determined. The values obtained for four grades of MCC and the coefficients of determination $\left(R^{2}\right)$ are presented in Table 5. Satisfactory fits are obtained and the surfaces fitted are plotted in Figure 17. 
Table 5. The values of coefficients obtained from fitting Equation 10 to data obtained for powder discharge in gravity fill.

\begin{tabular}{|c|c|c|c|c|c|c|c|}
\hline & $A_{00}$ & $A_{10}$ & $A_{01}$ & $A_{20}$ & $A_{11}$ & $A_{02}$ & $R^{2}$ \\
\hline PH101 & -13.9 & 232.2 & 1349 & -471.1 & -347.6 & $-2.36 \mathrm{E}+04$ & 0.94 \\
\hline PH102 & -19.9 & 153.7 & 2315 & -230.5 & -562.4 & $-4.27 \mathrm{E}+04$ & 0.90 \\
\hline PH200 & 10.84 & 81.49 & 834.6 & -66.65 & -1402 & $-1.52 \mathrm{E}+04$ & $0.57 *$ \\
\hline PH302 & -42.19 & 299.7 & 4793 & -540.8 & -465.7 & $-1.00 \mathrm{E}+05$ & 0.91 \\
\hline
\end{tabular}

*small variations in the differentail pressure has resulted in small coefficient of determination.
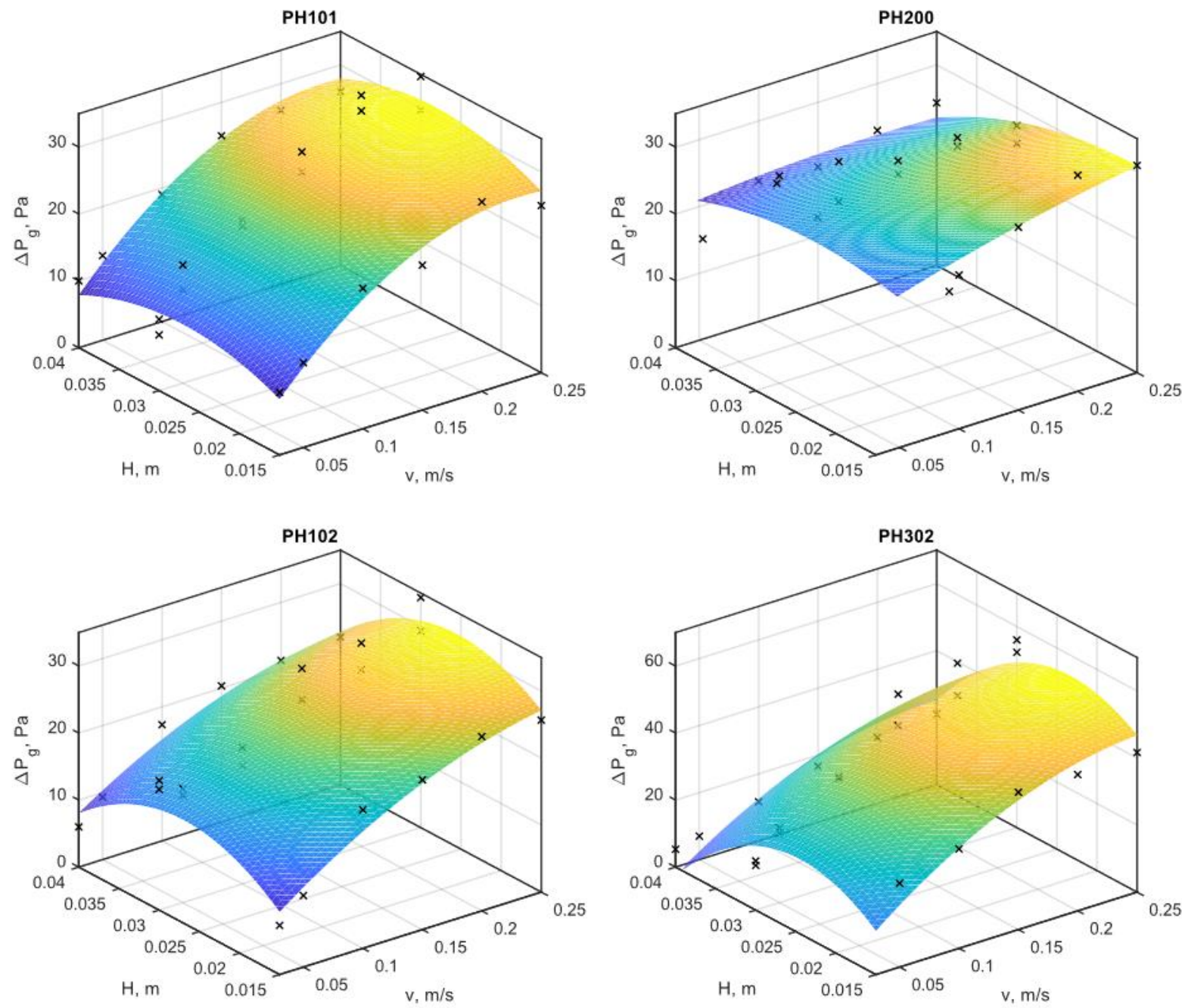

Figure 17. Polynomial surfaces fitted to the differential pressure data recorded for four grades of MCC as function of powder height and shoe velocity. 
Once the coefficients in Equation 10 are determined, this relation can be used in Equation 9 to calculate the mass discharged. The values of $m_{g}$ determined from this procedure are compared with the experimental results on Figure 18. A good agreement is observed between the calculated and experimental values. For clarity, it can be noted that Figure 17 uses the actual pressure difference measured experimentally, while Figure 18 uses an estimation of the pressure difference using Equation 10.

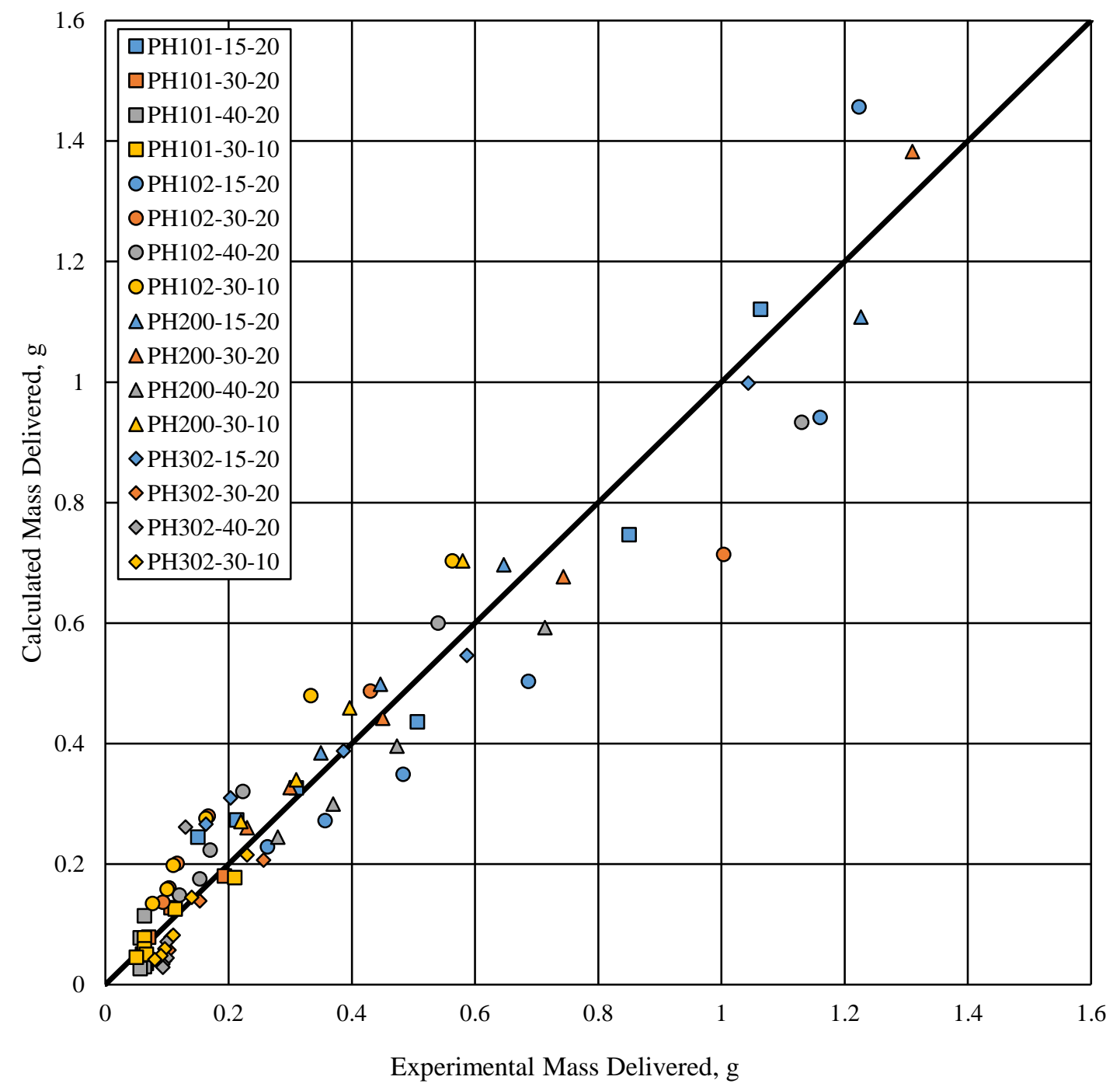

580 Figure 18. Experimental mass delivered in gravity fill vs. the calculated mass determined using the differential pressures calculated from Equation 10.

By estimating the pressure difference using Equation 10, only a small number of experiments are required to calibrate Equation 9 for a given material and system in use; thus Equation 9 can be used for process design and optimisation applications. 


\subsubsection{Suction fill mechanism}

The total mass of powder introduced into the die $(m)$ for the experiments performed involving suction fill mechanism can be defined as the sum of mass delivered in the suction fill stage $\left(m_{s}\right)$ and the mass delivered in gravity fill stage $\left(m_{g}\right)$.

$$
m=m_{s}+m_{g}
$$

590 Using Equation 9 the mass discharged into the die under gravity can be determined. Therefore, Equation 11 can be written as

$$
m=m_{s}+c_{g} \rho_{b} D^{2} L_{g}\left(\frac{H}{D}\right)^{a_{g}}\left(\frac{v \Delta P_{g}}{\rho_{b} g^{1.5} D^{1.5}}\right)^{n_{g}}
$$

where $L_{g}$ is the length of the shoe at which the powder is discharging under gravity fill mechanism.

Similar to Section 5.3.1, a model is developed to predict the mass of the powder delivered into the die in suction fill $\left(m_{s}\right)$. The main parameters involved in the process can be listed as: shoe velocity $(v)$, suction velocity $\left(v_{s}\right)$, differential pressure developed into the die during suction fill mechanism $\left(\Delta P_{S}\right)$, width of the die $(D)$, length of the shoe at which the powder is discharging under suction fill mechanism $\left(L_{s}\right)$, bulk density of the powder $\left(\rho_{b}\right)$, acceleration due to gravity $(g)$, viscosity of air $(\mu)$, coefficient of friction between particles $\left(\mu_{p}\right)$ and between particles and

600 the wall $\left(\mu_{p w}\right)$, powder permeability $(k)$, shape of the particles, adhesion between the particles and clearances in the system. Therefore, we have

$$
m_{s}=f\left(v_{s}, v_{d}, \Delta P_{s}, D, L_{s}, \rho_{b}, g, \mu, \mu_{p}, \mu_{p w}, k, \text { shape, adhesion, clearances }\right)
$$

Following the Buckingham $\Pi$ theorem (Gibbings 2011), and by taking $\rho_{b}, g$ and $D$ as independent parameters the $\pi$ groups of $\overline{m_{s}}, \overline{v_{s}}, \overline{v_{d}}$ and $\overline{\Delta P_{s}}$ are formed as:

$$
\begin{gathered}
\overline{m_{s}}=\frac{m_{s}}{\rho_{b} D^{2} L_{s}} \\
\bar{v}=\frac{v}{\sqrt{g D}} \\
\overline{v_{s}}=\frac{v_{s}}{\sqrt{g D}}
\end{gathered}
$$




$$
\overline{\Delta P_{s}}=\frac{\Delta P_{s}}{\rho_{b} g D}
$$

A model in the form of Equation 18 is then proposed to determine the mass delivered during 605 suction fill period.

$$
\frac{m_{s}}{\rho_{b} D^{2} L_{s}}=c_{s}\left(\frac{v}{\sqrt{g D}}\right)^{a_{s}}\left(\frac{v_{s}}{\sqrt{g D}}\right)^{b_{s}}\left(\frac{\Delta P_{s}}{\rho_{b} g D}\right)^{n_{s}}
$$

In this model, $c_{s}, a_{s}, b_{s}$ and $n_{s}$ are empirical constants based on material properties and processing parameters which are not included in the model.

To determine the mass discharged in suction, the powder mass delivered in gravity fill $\left(m_{g}\right)$ was determined using the coefficients presented in Table 4. For this purpose, the length at which the powder is discharging under gravity $\left(L_{g}\right)$ was calculated using Equation $19\left(L_{T}\right.$ is the total length of the shoe) and the differential pressures $\left(\Delta P_{g}\right)$ were determined from Equation 10 using the coefficients presented in Table 5. This enabled precise estimation of the pressures for the materials and system in use.

$$
L_{g}=L_{T}-L_{s}=L_{T}-\frac{v H_{d}}{v_{s}}
$$

In the next step, the values of $m_{s}$ were obtained from subtracting the total mass discharged into

615 the die $(m)$ by the values of $m_{g}$ determined using the above procedure. The values of $m_{s}$ were then used in fitting Equation 18 to determine the constants $c_{s}, a_{s}, b_{s}$ and $n_{s}$ as presented in Table 6. In Equation 18, the differential pressures were taken as the minimum pressure recorded during die filling process. The experiments in which the die was completely ( $\mathrm{PH} 200$ under $v=100 \mathrm{~mm} / \mathrm{s}$ ) filled were not considered in model development. results to Equation 18.

\begin{tabular}{|c|c|c|c|c|c|}
\hline Material & $c_{s}$ & $a_{s}$ & $b_{s}$ & $n_{s}$ & $R^{2}$ \\
\hline PH101 & 0.44 & -1.05 & 0.90 & 0.64 & 0.97 \\
\hline PH102 & 0.56 & -0.99 & 0.81 & 0.41 & 0.95 \\
\hline
\end{tabular}




\begin{tabular}{|c|c|c|c|c|c|}
\hline PH200 & 0.70 & -1.13 & 0.90 & 0.26 & 0.97 \\
\hline PH302 & 0.45 & -0.16 & 0.51 & 0.50 & 0.63 \\
\hline
\end{tabular}

The calculated mass discharged into the die under suction fill mechanism is compared with the experimental values on Figure 19. The labels represent the material and the shoe velocity used. For PH200 at $v=100 \mathrm{~mm} / \mathrm{s}$, the mass calculated using the model is larger than the experimental 625 values since the die was completely filled with powder. The model however, determines the mass delivered under suction with satisfactory accuracy. Larger discrepancies are observed for $v=300 \mathrm{~mm} / \mathrm{s}$.

The complete form of the model developed to determine the total mass discharged can be written as Equation 20.

$$
\begin{aligned}
m=c_{s} \rho_{b} D^{2} L_{s} & \left(\frac{v}{\sqrt{g D}}\right)^{a_{s}}\left(\frac{v_{s}}{\sqrt{g D}}\right)^{b_{s}}\left(\frac{\Delta P_{s}}{\rho_{b} g D}\right)^{n_{s}} \\
& +c_{g} \rho_{b} D^{2} L_{g}\left(\frac{H}{D}\right)^{a_{g}}\left(\frac{v \Delta P_{g}}{\rho_{b} g^{1.5} D^{1.5}}\right)^{n_{g}}
\end{aligned}
$$

630 To use this model, the empirical constants should be calibrated experimentally for the material and system in use while the differential pressure developed during gravity fill can be estimated using Equation 10. An equivalent equation to calculate $\Delta P_{S}$ requires further experiments.

Equation 20 can be used for estimating the flow behaviour of powders under differential pressure, for example the die fill in rotary tablet presses, which is illustrated next. 


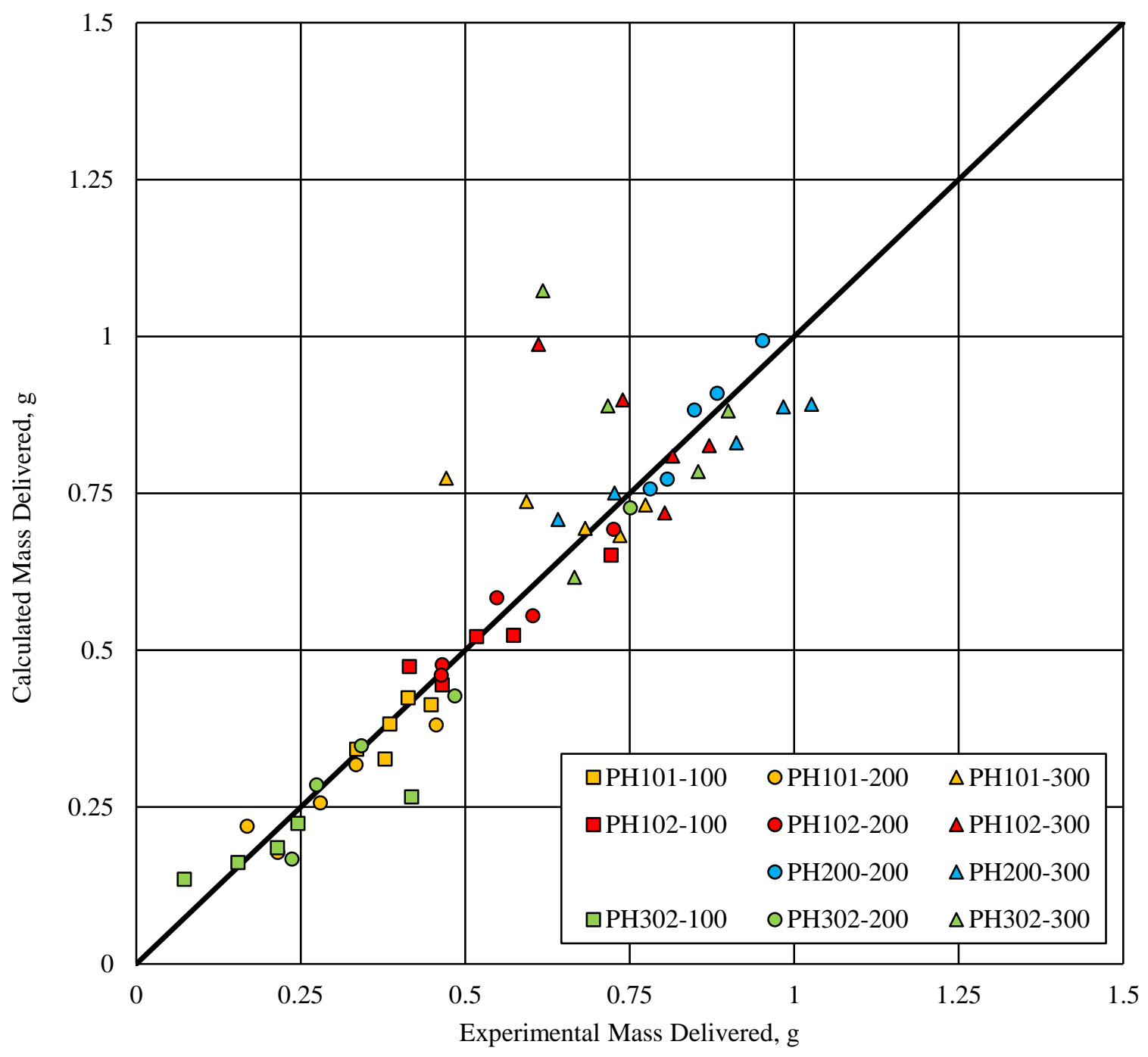

635

Figure 19. The mass delivered in suction fill calculated from Equation 18 vs. the experimental values for four grades of MCC.

\subsubsection{Rotary tablet press operation}

Pharmaceutical manufacturing relies on a variety of rotary tablet presses. The results from the

640 linear shoe-die system can be related to rotary tablet press geometry and operating parameters (defined in Figure 1). We return to the methodology presented by Sinka et al. (Sinka, et al. 2004) using Equation 20, which now considers not only gravity but also the suction fill mechanism. The operating conditions of a Fette 1000 tablet press are presented on Table 7.

Table 7. Operating conditions of a Fette 1000 rotary tablet press (Sinka, et al. 2004)

\begin{tabular}{|l|l|}
\hline Operating parameter & Value \\
\hline
\end{tabular}




\begin{tabular}{|c|c|}
\hline Press speed, $n$ & $0-75 \mathrm{rpm}$ \\
\hline Fill-o-matic speed, $n^{*}$ & $0-100 \mathrm{rpm}$ \\
\hline Radius of die table, $R$ & $157 \mathrm{~mm}$ \\
\hline Effective radius of feed wheel, $R^{*}$ & $78 \mathrm{~mm}$ \\
\hline Angle where die receives powder, $\alpha$ & $35^{\circ}$ \\
\hline Number of spokes of feed wheel, $N_{s}$ & 16 \\
\hline
\end{tabular}

645 Similar to (Sinka, et al. 2004), the press speed and the fill-o-matic speed were specified as 40 and $20 \mathrm{rpm}$ respectively. This gives an equivalent shoe velocity of approximately $v=500 \mathrm{~mm} / \mathrm{s}$. Based on the press geometry, the equivalent shoe length can be calculated as the length of the arc between two adjacent paddles of the feeder. Therefore

$$
L=\frac{2 \pi R \alpha}{360} \approx 95 \mathrm{~mm}
$$

It is also considered that $D=H_{d}=10 \mathrm{~mm}$ and the height of the powder is $H=20 \mathrm{~mm}$. From location of the suction cam it is noted that suction takes place over $1 / 3$ of the shoe length. Accordingly, the suction time $\left(t_{s}\right)$ and so the suction velocity are determined as $t_{s}=0.063 \mathrm{~s}$ and $v_{s}=150 \mathrm{~mm} / \mathrm{s}$ respectively. The die fill performance of four grades of MCC in a rotary tablet press under the processing conditions described above are estimated using Equation 20 with the values of the coefficients being taken from Section 5.3.1 and Section 5.3.2. Differential pressure in gravity was determined using Equation 9. However, no experimental data is available for $\Delta P_{S}$ for a shoe velocity of $v=500 \mathrm{~mm} / \mathrm{s}$. It is anticipated that since the shoe velocity is considerably larger than the values considered before, the differential pressures developed during suction fill $\left(\Delta P_{S}\right)$ would be larger than those measured in Section 5.2.2. Here, conservative value equal to the maximum pressure measured is considered for $\Delta P_{S}$ for each material.

Table 8 estimates the mass discharged, mass of full die and the number of passes required to fill the die for the four materials. Note that a fill cycle corresponds to 2.35 single shoe passes (Sinka, et al. 2004) for the operating conditions considered i.e. the spokes pass over the die cavity more than two times while the die is in the feeding zone. Suction fill initiates at the 
beginning of the filling cycle and the powder discharges under gravity only once suction fill is completed. Therefore, the contribution from suction fill is only considered for the first pass of the spokes.

In Table 8 it is shown that under the operating conditions specified, the die can be filled completely in a single pass of the spokes. Table 8 can be used to rank order the die fill performance of the powders under the specific operating conditions considered. Different operating conditions may yield different rank orders.

Table 8. Die fill performance of four grades of MCC in a rotary tablet press (operating conditions from Sinka et al. (Sinka, et al. 2004))

\begin{tabular}{|c|c|c|c|c|c|c|}
\hline Material & $m_{g}, \mathrm{~g}$ & $\Delta P_{s}, \mathrm{~Pa}$ & $m_{s}, \mathrm{~g}$ & $\begin{array}{c}\text { Total mass in } \\
\text { one pass, } \mathrm{g}\end{array}$ & $\begin{array}{c}\text { Total mass in } \\
\text { filling cycle } \\
(2.35 \text { passes }), \mathrm{g}\end{array}$ & $\begin{array}{c}\text { Mass of full } \\
\text { die }\end{array}$ \\
\hline PH101 & 0.009 & 65 & 0.464 & 0.473 & 0.515 & 0.24 \\
\hline PH102 & 0.019 & 61 & 0.540 & 0.559 & 0.644 & 0.24 \\
\hline PH200 & 0.018 & 22 & 0.448 & 0.465 & 0.542 & 0.28 \\
\hline PH302 & 0.008 & 69 & 0.994 & 1.002 & 1.039 & 0.30 \\
\hline
\end{tabular}

\section{6. Conclusions}

In pharmaceutical tablet manufacturing, the final properties of the tablets (e.g. weight uniformity) are determined by the mass of the powder discharged into the die in the feeding stage. Experiments using a linear shoe-die feeding system operating under gravity feed show that the mass of the powder introduced into the die reduces significantly by increasing the shoe velocity and the powder height in the shoe. On the other hand, the suction effect arising from the downward motion of the punch can significantly improve filling efficiency. It is argued that for a given shoe velocity, there exists an optimum suction velocity at which mass of the powder delivered into the die is the largest.

The changes in the differential pressure between the die and open atmosphere determine the amount of powder introduced. The pressure is influenced by material properties, powder 
discharge into the die, motion of the shoe and punch as well as the clearances in the system. It is shown that in gravity fill, powder flow results in a pressure gradient opposite to the direction of flow which inhibits further powder discharge while during suction fill, initial acceleration of the punch creates a pressure gradient in the direction of flow facilitating die fill. As a result 690 of powder entering the die the pressure starts to rise before the suction fill is completed. The pressure increase continues after the suction fill stage and the powder discharge switches to gravity fill mechanism.

It is observed that for powders with small particle size, large bulk density and small permeability, the pressure effects are more significant and suction have greater impact on the 695 mass discharged into the die. Local densification and particle interlocking resulted from selfweight of the powder and initial conditioning can negatively impact powder discharge in gravity fill mechanism through reduction in permeability while this can improve suction efficiency.

New models are proposed to determine the mass introduced into the die as a function of material and processing parameters. For gravity fill, the model developed by Schneider et al. (Schneider, et al. 2007) is modified to incorporate the influence of powder height in the shoe and the differential pressure developed between the die and open atmosphere on the mass delivered. The model includes three empirical coefficients which can be calibrated empirically. Unlike the model developed by Schneider, the coefficients remain constant for different sets of processing parameters.

For suction fill, the model is developed by considering the total mass delivered as the sum of the mass delivered in suction fill and the mass discharged under gravity fill mechanism. The suction fill model includes four empirical constants which remain constant for different processing parameters and can be calibrated experimentally. In order to use the model for 710 practical applications involving gravity and suction fill, preliminary experiments are necessary to determine the values of the empirical coefficients for a given powder material and to capture the influence of parameters not appearing in the model explicitly. The model can also be used to evaluate the influence of process parameters such as feeding velocity on the mass discharged into the die.

715 In order to use the proposed model for process design (e.g. a new powder delivery system) it is necessary to determine the differential pressure for the system considered. The differential pressures appearing in the model require experimental measurements carried out on the specific 
equipment, e.g. using typical punches with typical clearances on presses running at typical speeds.

720 The practical use of the proposed model proposed was illustrated by estimating the die fill performance of the four MCC materials on a rotary tablet press. Using typical data from the press kinematics an equivalent set of shoe and die velocities were determined. Under these circumstances the die would be filled effectively by all four materials even at lower press speeds. Table 8 can provide a rank order for the powders but it is specific to the operating

725 conditions considered. A powder considered as poor flowing by standard measures may equate or outperform free flowing powders. Different operating conditions may result in different rank orders of powder flowability when air pressure effects are at play.

\section{Acknowledgement}

The authors would like to thank FMC BioPolymer for providing the powders and Prof. M.

730 Ghadiri for allowing access to the Malvern Mastersizer 2000 at the University of Leeds. 


\section{Appendix}

Table A.1. Differential pressures measured for four grades of MCC in suction and gravity fill mechanisms under different shoe and suction velocities

\begin{tabular}{|c|c|c|c|c|c|c|c|c|c|}
\hline \multirow{2}{*}{ 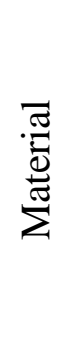 } & \multirow{2}{*}{ 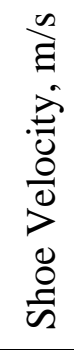 } & \multirow{2}{*}{ 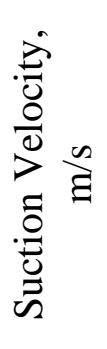 } & \multicolumn{2}{|c|}{ Differential Pressure, $\mathrm{Pa}$} & \multirow{2}{*}{ 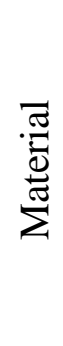 } & \multirow{2}{*}{ 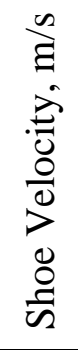 } & \multirow{2}{*}{ 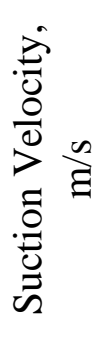 } & \multicolumn{2}{|c|}{ Differential Pressure, Pa } \\
\hline & & & $\begin{array}{c}\text { Suction } \\
\text { Fill }\end{array}$ & $\begin{array}{c}\text { Gravity } \\
\text { Fill }\end{array}$ & & & & $\begin{array}{c}\text { Suction } \\
\text { Fill }\end{array}$ & $\begin{array}{c}\text { Gravity } \\
\text { Fill }\end{array}$ \\
\hline \multirow{15}{*}{ 总 } & 0.1 & 0.1 & 15 & 21 & \multirow{15}{*}{$\begin{array}{l}8 \\
\stackrel{8}{1} \\
\text { I } \\
\text { I }\end{array}$} & 0.1 & 0.1 & 13 & 22 \\
\hline & 0.1 & 0.15 & 23 & 28 & & 0.1 & 0.15 & 14 & 25 \\
\hline & 0.1 & 0.2 & 25 & 32 & & 0.1 & 0.2 & 16 & 30 \\
\hline & 0.1 & 0.25 & 22 & 34 & & 0.1 & 0.25 & 15 & 27 \\
\hline & 0.1 & 0.3 & 19 & 35 & & 0.1 & 0.3 & 12 & 28 \\
\hline & 0.2 & 0.1 & 20 & 21 & & 0.2 & 0.1 & 24 & 31 \\
\hline & 0.2 & 0.15 & 16 & 18 & & 0.2 & 0.15 & 20 & 29 \\
\hline & 0.2 & 0.2 & 12 & 17 & & 0.2 & 0.2 & 20 & 33 \\
\hline & 0.2 & 0.25 & 7 & 19 & & 0.2 & 0.25 & 12 & 24 \\
\hline & 0.2 & 0.3 & 10 & 20 & & 0.2 & 0.3 & 14 & 26 \\
\hline & 0.3 & 0.1 & 62 & 62 & & 0.3 & 0.1 & 19 & 21 \\
\hline & 0.3 & 0.15 & 61 & 61 & & 0.3 & 0.15 & 22 & 28 \\
\hline & 0.3 & 0.2 & 58 & 59 & & 0.3 & 0.2 & 19 & 24 \\
\hline & 0.3 & 0.25 & 65 & 68 & & 0.3 & 0.25 & 14 & 25 \\
\hline & 0.3 & 0.3 & 60 & 61 & & 0.3 & 0.3 & 12 & 25 \\
\hline \multirow{15}{*}{$\frac{\sqrt{O}}{\underline{D}}$} & 0.1 & 0.1 & 21 & 30 & \multirow{15}{*}{ 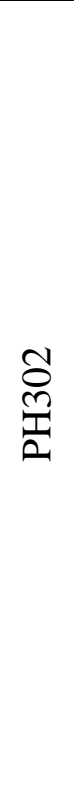 } & 0.1 & 0.1 & 20 & 27 \\
\hline & 0.1 & 0.15 & 15 & 24 & & 0.1 & 0.15 & 21 & 29 \\
\hline & 0.1 & 0.2 & 17 & 26 & & 0.1 & 0.2 & 19 & 27 \\
\hline & 0.1 & 0.25 & 15 & 28 & & 0.1 & 0.25 & 18 & 28 \\
\hline & 0.1 & 0.3 & 14 & 27 & & 0.1 & 0.3 & 15 & 35 \\
\hline & 0.2 & 0.1 & 24 & 25 & & 0.2 & 0.1 & 47 & 47 \\
\hline & 0.2 & 0.15 & 17 & 21 & & 0.2 & 0.15 & 24 & 25 \\
\hline & 0.2 & 0.2 & 22 & 25 & & 0.2 & 0.2 & 21 & 22 \\
\hline & 0.2 & 0.25 & 15 & 19 & & 0.2 & 0.25 & 6 & 14 \\
\hline & 0.2 & 0.3 & 15 & 20 & & 0.2 & 0.3 & 21 & 21 \\
\hline & 0.3 & 0.1 & 56 & 56 & & 0.3 & 0.1 & 52 & 52 \\
\hline & 0.3 & 0.15 & 54 & 55 & & 0.3 & 0.15 & 53 & 53 \\
\hline & 0.3 & 0.2 & 48 & 51 & & 0.3 & 0.2 & 69 & 70 \\
\hline & 0.3 & 0.25 & 40 & 44 & & 0.3 & 0.25 & 68 & 69 \\
\hline & 0.3 & 0.3 & 61 & 66 & & 0.3 & 0.3 & 50 & 50 \\
\hline
\end{tabular}




\section{References}

Baserinia, R., Sinka, I.C., 2018. Mass flow rate of fine and cohesive powders under differential air pressure. Powder Technology, 334, 173-182. doi:

//doi.org/10.1016/j.powtec.2018.04.041.

Baserinia, R., Sinka, I.C., Rajniak, P., 2016. Vacuum assisted flow initiation in arching powders. Powder Technol, 301, 493-502.

Bocchini, G.F., 1987. Influence of small die width on filling and compacting densities. Powder Metallurgy, 30, 261-266.

Burch, S.F., Cocks, A.C.F., Prado, J.M., Tweed, J.H., 2007. Modelling of powder die compaction. , 131-150.

Carman, P.C., 1937. Fluid flow through granular beds. Trans.Inst.Chem.Eng., 15, 150-166.

Carr, R.L., 1965. Classifying flow properties of solids. Chem.Eng., 1, 69-72.

Carrigy, M.A., 1970. Experiments on the angles of repose of granular materials 1.

Sedimentology, 14, 147-158.

Darcy, H., 1856. Les fontaines publiques de la ville de Dijon: exposition et application...

Freeman, R., 2007. Measuring the flow properties of consolidated, conditioned and aerated powders - a comparative study using a powder rheometer and a rotational shear cell. Powder Technol, 174, 25-33.

Freeman, R., 2004. The importance of air content on the rheology of powders: an empirical study. Am. Lab., 36, 8-10.

Gibbings, J.C., 2011. Dimensional analysis.

Grey, R.O., Beddow, J.K., 1969. On the Hausner ratio and its relationship to some properties of metal powders. Powder Technol, 2, 323-326.

Grymonpré, W., Vanhoorne, V., Van Snick, B., Prudilova, B.B., Detobel, F., Remon, J.P., De Beer, T., Vervaet, C., 2018. Optimizing feed frame design and tableting process parameters to increase die-filling uniformity on a high-speed rotary tablet press. Int. J. Pharm., 548, 5461.

Guo, Y., Kafui, K.D., Wu, C., Thornton, C., Seville, J.P., 2009. A coupled DEM/CFD analysis of the effect of air on powder flow during die filling. AIChE J., 55, 49-62.

Guyoncourt, D., Tweed, J.H., 2003. Measurements for powder flow. Proceedings of PM2003, $10-22$.

Haskins, J.J., Jandeska, W.F., 1999. Powder flow and die filling studies using computed tomography., 10. 
Jackson, S., Sinka, I.C., Cocks, A.C.F., 2007. The effect of suction during die fill on a rotary tablet press. European Journal of Pharmaceutics and Biopharmaceutics, 65, 253-256. doi: //doi.org/10.1016/j.ejpb.2006.10.008.

Jallo, L.J., Ghoroi, C., Gurumurthy, L., Patel, U., Davé, R.N., 2012. Improvement of flow and bulk density of pharmaceutical powders using surface modification. International Journal of Pharmaceutics, 423, 213-225. doi: //doi.org/10.1016/j.ijpharm.2011.12.012.

Jenike, A.W., 1964. Storage and flow of solids. Bulletin No. 123 of the Utah engineering experiment station, University of Utah, 53.

Kozeny, J., 1927. Ueber kapillare Leitung des Wassers im Boden. Sitzungsber Akad. Wiss., Wien, 136, 271-306.

Mendez, R., Muzzio, F., Velazquez, C., 2010. Study of the effects of feed frames on powder blend properties during the filling of tablet press dies. Powder Technol, 200, 105-116.

Mills, L.A., Sinka, I.C., 2013. Effect of particle size and density on the die fill of powders. European Journal of Pharmaceutics and Biopharmaceutics, 84, 642-652. doi:

//doi.org/10.1016/j.ejpb.2013.01.012.

Sawayama, T., Seki, Y., 1999. The Effect of Filling Condition on Die Filling. Advances in Powder Metallurgy and Particulate Materials, 1, 2-61.

Schiano, S., Chen, L., Wu, C., 2017. The effect of dry granulation on flow behaviour of pharmaceutical powders during die filling. Powder Technology. doi:

//doi.org/10.1016/j.powtec.2017.08.064.

Schneider, L., Sinka, I.C., Cocks, A., 2007. Characterisation of the flow behaviour of pharmaceutical powders using a model die-shoe filling system. Powder Technol, 173, 59-71.

Schulze, D., 1994a. Development and application of a novel ring shear tester. Aufbereitungs Technik, 35, 524-535.

Schulze, D., 1994b. A new ring shear tester for flowability and time consolidation measurements. Proceedings of 1st International Particle Technology Forum, 11-16.

Seville, J.P., Tüzün, U., Clift, R., 2012. Processing of particulate solids. , 9.

Sinka, I.C., Cocks, A.C.F., 2009. Evaluating the flow behaviour of powders for die fill performance. Powder Metallurgy, 52, 8-11. doi: 10.1179/174329009X441736.

Sinka, I.C., Schneider, L.C.R., Cocks, A.C.F., 2004. Measurement of the flow properties of powders with special reference to die fill. International Journal of Pharmaceutics, 280, 27-38. doi: //doi.org/10.1016/j.ijpharm.2004.04.021.

United States Pharmacopeia and National Formulary[USP38-NF33], 2015. Dietary Supplements Compendium. , 1, 820. 
Vemavarapu, C., Surapaneni, M., Hussain, M., Badawy, S., 2009. Role of drug substance material properties in the processibility and performance of a wet granulated product. International Journal of Pharmaceutics, 374, 96-105. doi:

//doi.org/10.1016/j.ijpharm.2009.03.014.

Walker, D.M., 1966. An approximate theory for pressures and arching in hoppers. Chemical Engineering Science, 21, 975-997. doi: //doi.org/10.1016/0009-2509(66)85095-9.

Wu, C.-., Cocks, A.C.F., 2004. Flow behaviour of powders during die filling. Powder Metallurgy, 47, 127-136. doi: 10.1179/003258904225015617.

Wu, C.Y., Dihoru, L., Cocks, A., 2004. An experimental investigation of filling density variation. J. Mater. Process. Technol.

Wu, C., Cocks, A.C., 2006. Numerical and experimental investigations of the flow of powder into a confined space. Mech. Mater., 38, 304-324.

Wu, C., Dihoru, L., Cocks, A.C., 2003. The flow of powder into simple and stepped dies. Powder Technol, 134, 24-39.

Wu, C., Guo, Y., 2012. Numerical modelling of suction filling using DEM/CFD. Chemical Engineering Science, 73, 231-238. doi: //doi.org/10.1016/j.ces.2012.01.048.

Zakhvatayeva, A., Zhong, W., Makroo, H.A., Hare, C., Wu, C.Y., 2018. An experimental study of die filling of pharmaceutical powders using a rotary die filling system. Int. J. Pharm., $553,84-96$. 